\title{
Serotonin receptor 4 in the hippocampus modulates mood and anxiety
}

\author{
Remzi Karayol (10 ${ }^{1} \cdot$ Lucian Medrihan $^{2} \cdot$ Jennifer L. Warner-Schmidt ${ }^{3} \cdot$ Ben W. Fait $^{1} \cdot$ Meghana N. Rao $^{1} \cdot$ \\ Eva B. Holzner ${ }^{1} \cdot$ Paul Greengard $\mathbb{B}^{2} \cdot$ Nathaniel Heintz $\mathbb{B}^{1,4} \cdot$ Eric F. Schmidt $\mathbb{D}^{1}$
}

Received: 13 September 2019 / Revised: 2 December 2020 / Accepted: 9 December 2020 / Published online: 13 January 2021

(c) The Author(s) 2021. This article is published with open access

\begin{abstract}
Serotonin receptor $4\left(5-\mathrm{HT}_{4} \mathrm{R}\right)$ plays an important role in regulating mood, anxiety, and cognition, and drugs that activate this receptor have fast-acting antidepressant (AD)-like effects in preclinical models. However, $5-\mathrm{HT}_{4} \mathrm{R}$ is widely expressed throughout the central nervous system (CNS) and periphery, making it difficult to pinpoint the cell types and circuits underlying its effects. Therefore, we generated a Cre-dependent 5- $\mathrm{HT}_{4} \mathrm{R}$ knockout mouse line to dissect the function of $5-\mathrm{HT}_{4} \mathrm{R}$ in specific brain regions and cell types. We show that the loss of functional 5- $\mathrm{HT}_{4} \mathrm{R}$ specifically from excitatory neurons of hippocampus led to robust $\mathrm{AD}$-like behavioral responses and an elevation in baseline anxiety. 5-HT $\mathrm{R}_{4}$ was necessary to maintain the proper excitability of dentate gyrus (DG) granule cells and cell type-specific molecular profiling revealed a dysregulation of genes necessary for normal neural function and plasticity in cells lacking 5-HT $\mathrm{H}_{4}$. These adaptations were accompanied by an increase in the number of immature neurons in ventral, but not dorsal, dentate gyrus, indicating a broad impact of 5- $\mathrm{HT}_{4} \mathrm{R}$ loss on the local cellular environment. This study is the first to use conditional genetic targeting to demonstrate a direct role for hippocampal 5- $\mathrm{HT}_{4} \mathrm{R}$ signaling in modulating mood and anxiety. Our findings also underscore the need for cell type-based approaches to elucidate the complex action of neuromodulatory systems on distinct neural circuits.
\end{abstract}

\section{Introduction}

Emotion is governed by a complex neural circuit comprised of anatomically and functionally distinct components that are distributed throughout the CNS. Functional imaging and postmortem analyses of brains of patients suffering from

Deceased: Paul Greengard

Supplementary information The online version of this article (https:// doi.org/10.1038/s41380-020-00994-y) contains supplementary material, which is available to authorized users.

Eric F. Schmidt

eschmidt@ rockefeller.edu

1 Laboratory of Molecular Biology, The Rockefeller University, New York, NY 10065, USA

2 Laboratory of Molecular and Cellular Neuroscience, The Rockefeller University, New York, NY 10065, USA

3 NeuroJenic Consulting LLC, Garden City, NY 11530, USA

4 Howard Hughes Medical Institute, The Rockefeller University, New York, NY 10065, USA depression and/or anxiety disorders suggest a dysfunction in regions of the brain that control emotion, including limbic structures such as the hippocampus, amygdala, prefrontal cortex, and hypothalamus [1,2]. Each of these areas is strongly modulated by the neurotransmitter serotonin (5-HT) while drugs that target 5-HT signaling, such as selective serotonin reuptake inhibitors (SSRIs), are a firstline treatment for affective disorders [3]. The widespread influence of 5-HT on numerous cognitive and behavioral processes leads to many unwanted side effects due to offtarget engagement of AD drugs [4], and functional and anatomical separation of the neural substrates underlying pathology from those mediating therapeutic responses $[5,6]$. This notion is reinforced by regional differences in the expression and regulation of genes and gene networks across the emotion circuit in disease-related contexts [7, 8]. Improved treatments for these diseases are dependent on a more precise understanding of cell types and molecular pathways mediating 5-HT-dependent signaling.

The 5- $\mathrm{HT}_{4}$ receptor $\left(5-\mathrm{HT}_{4} \mathrm{R}\right)$ is one of over 14 known 5-HT receptors in mammals and is strongly linked to $\mathrm{AD}$ responses [9]. 5- $\mathrm{HT}_{4} \mathrm{R}$ is an excitatory $\mathrm{G}_{\mathrm{s}}$-coupled receptor 
that activates the cyclic AMP (cAMP)-PKA pathway and promotes the excitability of neurons $[10,11]$. Changes in $5-\mathrm{HT}_{4} \mathrm{R}$ binding were observed in several brain regions in depressed patients [12,13] while polymorphisms in HTR4 (the gene that encodes $5-\mathrm{HT}_{4} \mathrm{R}$ ) were associated with a susceptibility to unipolar depression [14]. In preclinical studies, short-term treatment with $5-\mathrm{HT}_{4} \mathrm{R}$ agonists, including RS67333, has anxiolytic and antidepressant properties and mimics the cellular and molecular AD responses achieved after chronic SSRI administration [15-19]. In addition, $5-\mathrm{HT}_{4} \mathrm{R}$ agonists potentiate the effects of SSRIs [20] while constitutive Htr4 knockout mice have reduced behavioral responses to acute stress and novelty [21]. 5-HT $\mathrm{H}_{4} \mathrm{R}$ has also been linked to the regulation of adult neurogenesis in the dentate gyrus (DG) $[16,17]$ which is a reliable readout of $\mathrm{AD}$ efficacy and may underlie some therapeutic AD effects [22].

$5-\mathrm{HT}_{4} \mathrm{R}$ is highly expressed in many brain regions linked to mood and anxiety, namely the hippocampus, amygdala, prefrontal cortex, and striatum [10, 23], as well as peripheral tissues such as the gut, heart, and adrenal glands [24]. Such widespread expression in the CNS and periphery complicates the use of $5-\mathrm{HT}_{4} \mathrm{R}$ as a viable therapeutic target for mood, as its activation can lead to significant gastrointestinal and cardiac complications [25, 26]. Most in vivo studies investigating $5-\mathrm{HT}_{4} \mathrm{R}$ function have relied on systemic pharmacological approaches or constitutive deletion. Therefore, employing a cell type centered approach to elucidate distinct roles for $5-\mathrm{HT}_{4} \mathrm{R}$ signaling in discrete circuits and/or cell types will facilitate the development of more precise and efficacious therapies.

To achieve this, we generated mice harboring a conditional mutant allele to delete functional $5-\mathrm{HT}_{4} \mathrm{R}$ from genetically targeted cell populations expressing Cre recombinase. We used this line to investigate the role of $5-\mathrm{HT}_{4} \mathrm{R}$ signaling in hippocampus, which plays a central role in affective behaviors $[27,28]$, and where $5-\mathrm{HT}_{4} \mathrm{R}$ is expressed at high levels [29]. We report that the loss of $5-\mathrm{HT}_{4} \mathrm{R}$ specifically from excitatory neurons of the hippocampus led to AD-like effects at the behavioral, cellular, and molecular levels which were accompanied by an anxiogenic phenotype. Cell type-specific molecular profiling revealed that the ventral dentate gyrus (vDG) granule cells (GCs) underwent robust molecular adaptations in the absence of $5-\mathrm{HT}_{4} \mathrm{R}$. In addition, we observed enhanced neurogenesis in the vDG and reduced excitability of mature vDG GCs in the absence of $5-\mathrm{HT}_{4} \mathrm{R}$. Our data reinforce a direct role for hippocampal $5-\mathrm{HT}_{4} \mathrm{R}$ in mediating affective behaviors, likely through the regulation of relevant intracellular pathways and neural excitability, and uncover an unexpected functional complexity within the hippocampal circuit due to the differential effect on depression- and anxiety-related behaviors.

\section{Results}

\section{Generation and validation of an $\mathrm{Htr} 4^{\text {Floxed }}$ mouse line}

To study the function of the $5-\mathrm{HT}_{4} \mathrm{R}$ in specific cell types, we generated a novel mouse line $\left(\mathrm{Htr} 4^{\text {Floxed }}\right)$ to conditionally drive the deletion of functional $5-\mathrm{HT}_{4} \mathrm{R}$ from genetically defined cell populations using the Cre/loxP system (Fig. 1a). Homologous recombination was used to insert loxP sites flanking exon 5 of the mouse Htr4 gene, which encodes the fourth transmembrane domain of 5-HT 4 R (Fig. S1a and Document S1). In silico translation analysis predicted that the deletion of exon 5 would cause a frame shift mutation and the introduction of stop codons, including one right after the deletion site (Fig. S1b), leading to a truncated, unstable protein, that is unable to be inserted into the membrane, transduce a signal, and resulting in animals harboring a null $\mathrm{Htr} 4$ allele.

Because Htr4 is highly expressed in the hippocampal formation [29], we validated the deletion of exon 5 and the loss of functional $5-\mathrm{HT}_{4} \mathrm{R}$ by generating a hippocampusspecific Htr4 conditional knockout. The GENSAT BAC transgenic Drd3-Cre driver line KI198 (KI198 ${ }^{\mathrm{Cre}}$ ) was utilized since Cre recombinase expression was primarily limited to hippocampus [30]. The KI $198^{\text {Cre }}$ did not fully recapitulate $\operatorname{Drd} 3$ gene expression since the only visible expression outside of the hippocampus were a few scattered cells in ventromedial forebrain and islands of Calleja (www. gensat.org; Figs. $1 \mathrm{~b}$ and S2b). Homozygous Htr4 ${ }^{\text {Floxed }}$ mice were crossed to $\mathrm{KI} 198^{\mathrm{Cr}}$ mice to generate $\mathrm{KI} 198^{\mathrm{Cre}}$ :: Htr4 ${ }^{\text {Floxed }}$ (cKO) mice (Fig. S1c). Quantitative RT-PCR (qRT-PCR) using probes spanning Htr4 exons 4 and 5 (4-5) on RNA from dorsal and ventral subdivisions of the CA fields and DG revealed negligible expression of exon 5 in cKO samples compared to Cre-negative littermates (WT; Fig. 1c). In contrast, probes spanning exons 3-4 or 6-7 showed comparable expression between genotypes (Fig. S1e). These data confirm the generation of a mutant $\mathrm{Htr} 4$ transcript lacking exon $5\left(\mathrm{Htr}^{\text {delE5}}\right)$ following Cremediated recombination in $\mathrm{cKO}$ mice.

Since $5-\mathrm{HT}_{4} \mathrm{R}$ is a $\mathrm{G}_{\mathrm{s}}$-coupled receptor that activates intracellular cAMP upon ligand binding [10], we employed a cell culture-based cAMP induction assay to test the signaling ability of the mutant receptor. Expression vectors for mutant Htr4 ${ }^{\text {delEs }}$ (delE5) and intact Htr4 (WT) were made by cloning each transcript from total RNA samples isolated from the hippocampus of a cKO mouse or a WT littermate, respectively. The constructs were transfected into HEK293T cells which were stimulated in the presence of IBMX, a phosphodiesterase inhibitor to allow accumulation of newly converted cAMP. Intact WT expression led to five-fold higher baseline levels of cAMP than of mutant 
a

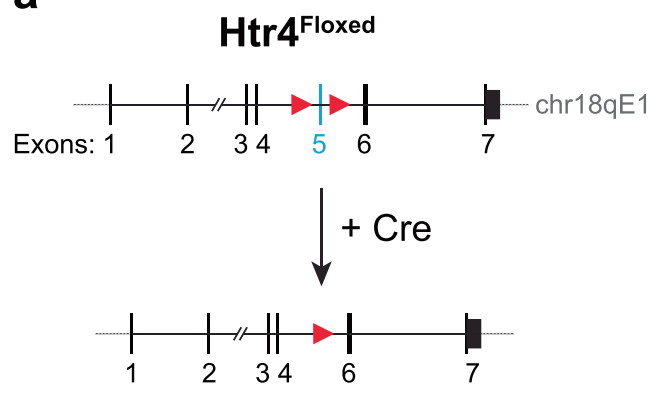

b
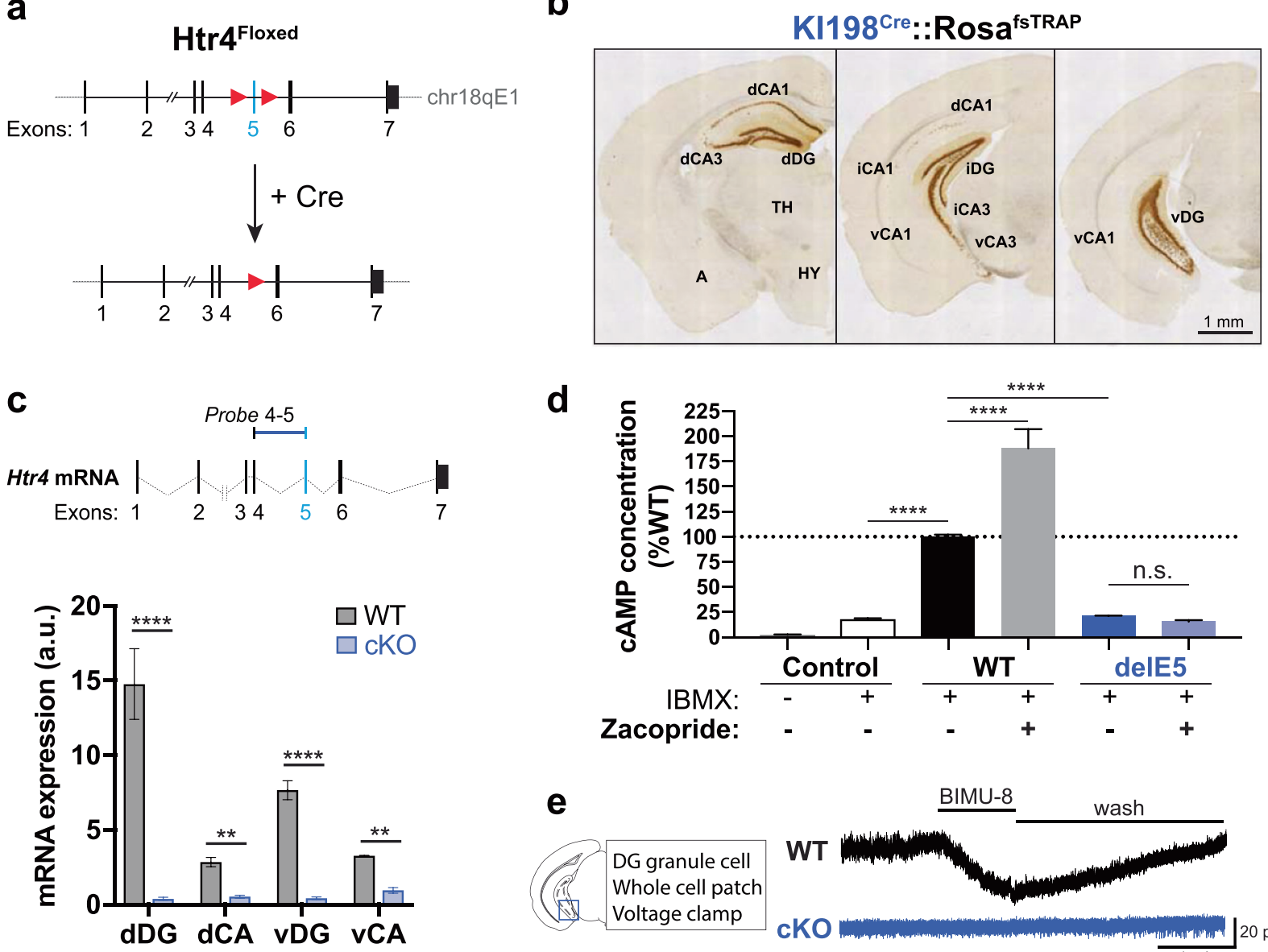

Fig. 1 Generation and validation of an $\mathrm{Htr}^{\text {Floxed }}$ mouse line. a Schematic of $\mathrm{Htr}^{\text {Floxed }}$ allele. LoxP sites (red triangles) were inserted to flank Htr4 exon 5 (light blue bar) for Cre-mediated excision. b Low magnification anti-EGFP immunohistology of coronal brain sections from a KI198 ${ }^{\mathrm{Cre}}:$ :Rosa26 $6^{\mathrm{fTRAP}}$ mouse showing Cre expression in the hippocampus. dCA, iCA, vCA1/3: dorsal, intermediate, ventral CA1/3 fields, respectively; A: amygdala; TH: thalamus; HY: hypothalamus. c Schematic of the TaqMan probe spanning Htr4 exons 4 and 5 (Probe 4-5) is shown at top. Below, qRT-PCR (mean \pm SEM) quantification showing diminished expression of Htr4 transcripts containing exon 5 along the dorsoventral axis of the

delE5 or EGFP (control) (Fig. 1d). Stimulation with zacopride, a potent $5-\mathrm{HT}_{4} \mathrm{R}$ agonist induced an $88 \%$ increase in cAMP production in cells expressing WT but did not significantly alter cAMP levels in those expressing delE5. These results suggest that exon 5 deletion leads to a nonfunctional receptor in vitro.

To test the functionality of mutant $5-\mathrm{HT}_{4} \mathrm{R}$ in intact hippocampal neurons, we performed whole-cell voltage clamp recordings from DG GCs in acute hippocampal slices from cKO mice and WT littermates. The addition of the 5- $\mathrm{HT}_{4} \mathrm{R}$ agonist, BIMU-8, induced an inward current in WT GCs indicating a depolarizing effect due to the activation of 5-HT ${ }_{4} \mathrm{R}$ (Fig. 1e), consistent with previous reports [11]. In contrast, cKO GCs did not respond to BIMU-8, validating
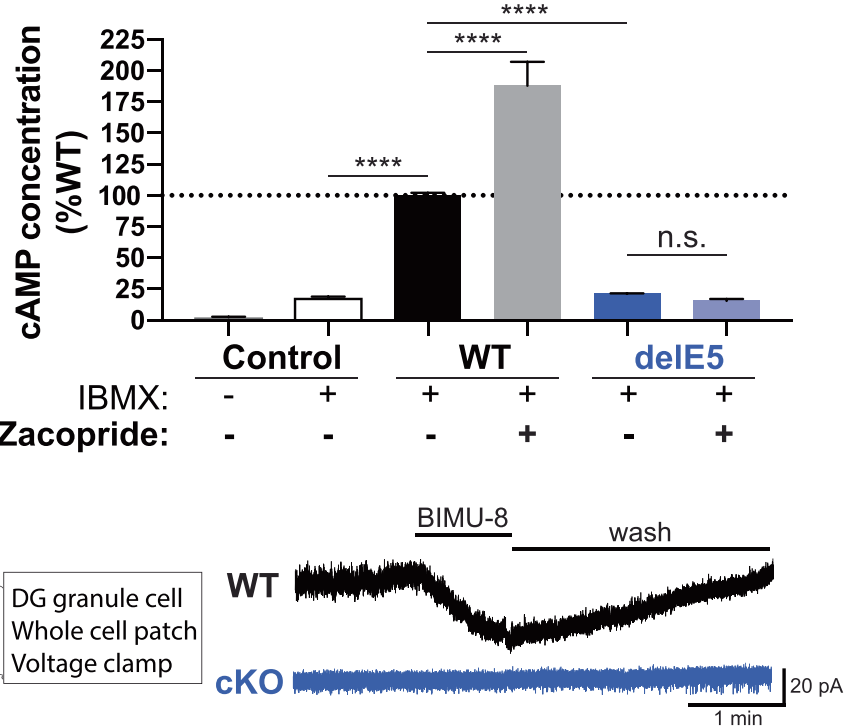

hippocampus in Cre-negative (WT, gray) and cKO (blue) mice. Twoway ANOVA: genotype factor: $\mathrm{F}(1,24)=439.0, p<0.0001$ followed by post hoc Fisher's LSD test. $n=2-6$ per group. d Quantification (mean \pm SEM) of cAMP induction in HEK293T cells expressing EGFP (Control), intact 5- $\mathrm{HT}_{4} \mathrm{R}$ (WT), or Htr4 ${ }^{\text {delE5 }}$ (del5) in the presence or absence of the 5- $\mathrm{HT}_{4} \mathrm{R}$ agonist, zacopride. One-way ANOVA followed by post hoc Fisher's LSD test, $n=4$ per group. e Representative traces of whole-cell voltage clamp recordings from DG GC in WT and cKO mice with bath administration of $10 \mathrm{mM}$ BIMU-8. Scale bar: $1 \mathrm{~min}, 20 \mathrm{pA}$. Fisher's LSD test, $* * * * p<0.0001$, $* * * p<$ $0.001, * * p<0.01$, n.s. $p>0.05$.

the absence of functional 5- $\mathrm{HT}_{4} \mathrm{R}$ in DG GCs in cKO mice at the electrophysiological level. Together with the cAMP activation assay, these results indicate that the deletion of exon 5 in cKO mice resulted in a functionally null receptor. We did not notice an obvious spontaneous seizure phenotype in the cKOs.

\section{KI198 ${ }^{\mathrm{Cre}}$ expression is restricted to excitatory neurons in the hippocampus}

To determine the identity of the Cre-expressing cells in the hippocampus of KI198 ${ }^{\mathrm{Cre}}$ mice, we crossed them to the Rosa26 $6^{\text {fsTRAP }}$ Cre-dependent reporter line [31], in which EGFP is fused to ribosomal protein L10a (EGFPL10a). 
Anti-GFP immunofluorescent staining of coronal brain sections from $\mathrm{KI} 198^{\mathrm{Cre}}::$ Rosa $26^{\text {fsTRAP }}$ mice revealed labeled cells along the dorsoventral axis of the hippocampus, including a subset of cells in dorsal CA1 (dCA1), dorsal CA3 (dCA3), ventral CA3 (vCA3), and most cells in the granule cell layer (GCL) and hilus along the dorsoventral axis of the DG (Fig. 2a, c). Few GFP-expressing cells were

a

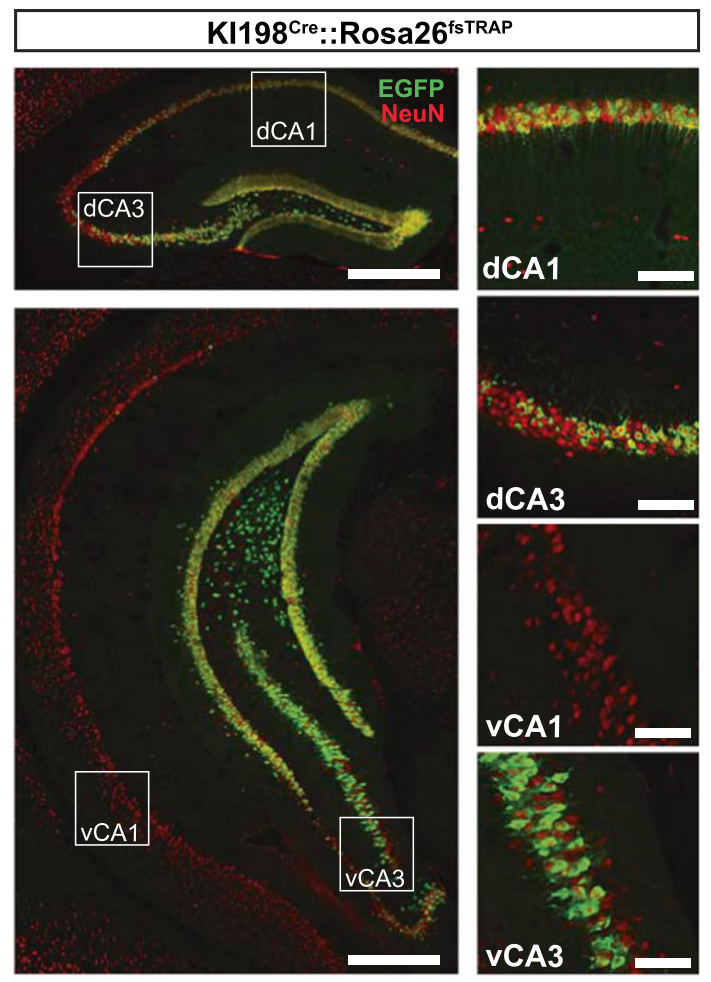

visible in ventral CA1 (vCA1). All GFP-expressing cells in CA fields were co-labeled with neuronal marker, NeuN, but not the GABAergic interneuron marker, glutamate decarboxylase (GAD67; Fig. S2c), suggesting KI198 ${ }^{\mathrm{Cre}}$ primarily labels excitatory pyramidal neurons in these regions. In DG, GFP was detected in all of the calbindin (CBD)expressing mature GCs and calretinin (CRT)-expressing

b
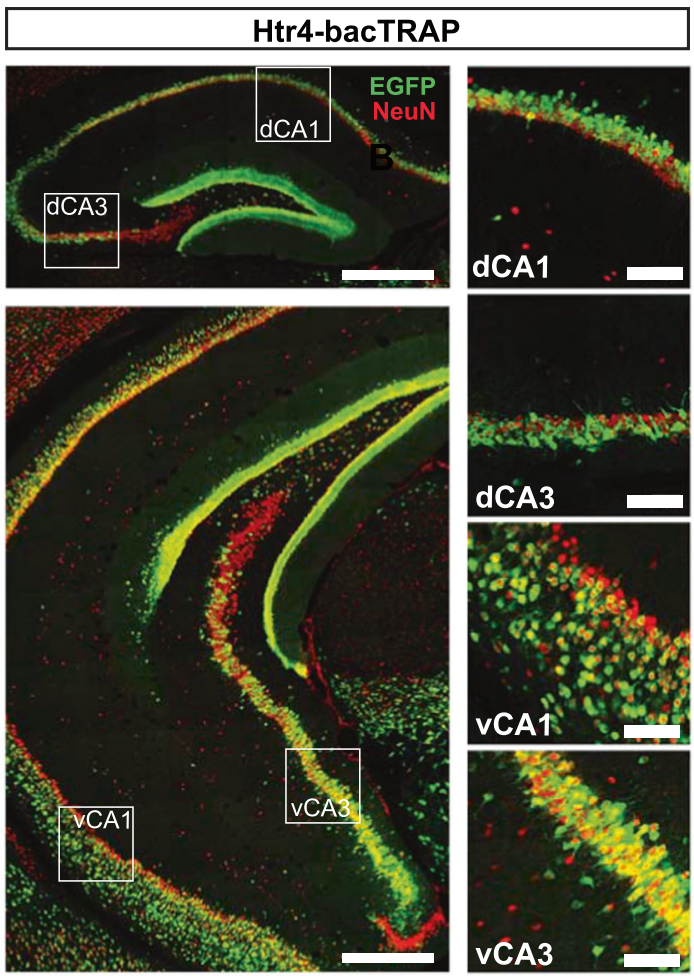

C

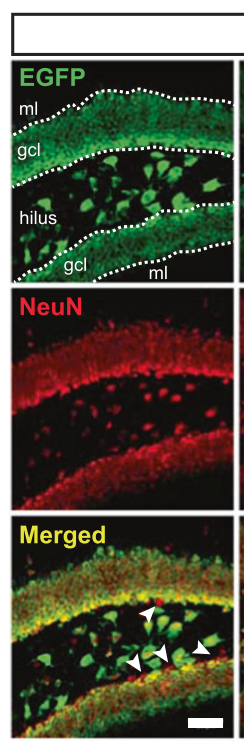

Neuron

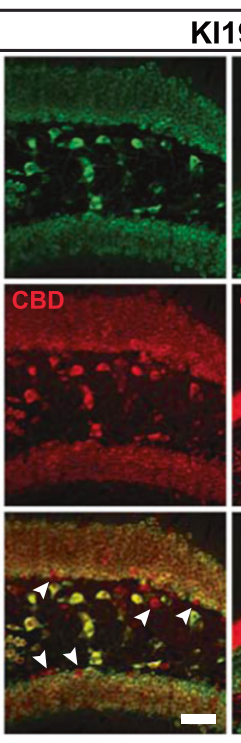

GC
Kl198 ${ }^{\text {cre }}:$ Rosa26 $6^{\text {fsTRAP }}$

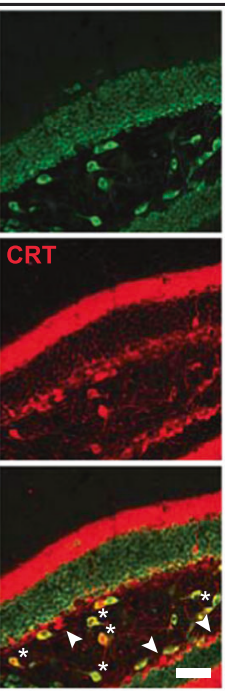

Mossy Cell / Immature $\mathrm{N}$.

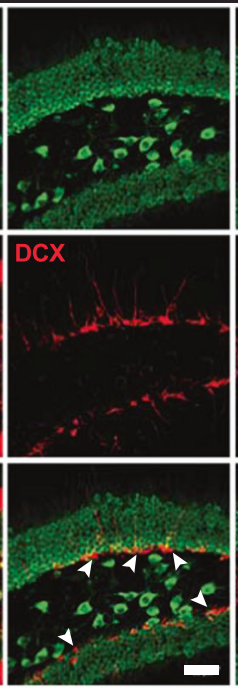

Immature Neuron d

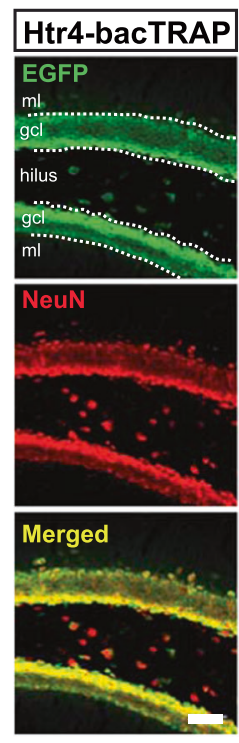

Neuron 
Fig. $2 \mathrm{KI} \mathrm{Kg}^{\mathrm{Cre}}$ expression is restricted to mature excitatory neurons in the hippocampus. a Anti-EGFP (green) and anti-NeuN (red) immunofluorescent confocal images of coronal hippocampal sections at the level of dorsal (top left) and ventral (bottom left) hippocampus from a $\mathrm{KI}_{198}{ }^{\mathrm{Cre}}::$ Rosa ${ }^{\text {fsTRAP }}$ mouse. Dorsal and ventral CA1 and CA3 fields (white boxes) are shown at higher magnification on the right. Scale bars: $500 \mu \mathrm{m}$ (left panels) or $100 \mu \mathrm{m}$ (right panels). b Anti-EGFP (green) and anti-NeuN (red) immunofluorescent confocal images of coronal sections at the level of dorsal (top left) and ventral (bottom left) hippocampus from an Htr4-bacTRAP mouse. Dorsal and ventral CA1 and CA3 fields (white boxes) are shown at higher magnification on the right. Scale bars: $500 \mu \mathrm{m}$ (left panels) or $100 \mu \mathrm{m}$ (right panels). c Immunofluorescent confocal images showing neuronal-type specific marker (red) and EGFP (green) expression in coronal sections through the DG of KI198 ${ }^{\mathrm{Cre}}::$ Rosa ${ }^{\text {fsTRAP }}$ mice. Cells labeled with a neuron-type marker but not EGFP (arrowheads) and cells double-labeled with hilar mossy cell marker CRT and EGFP (asterisks) are indicated. ml: molecular layer, gcl: granule cell layer. Scale bars, $50 \mu \mathrm{m}$. d Immunofluorescent confocal images of coronal sections through the DG of Htr4-bacTRAP mice labeled with anti-NeuN (red) and anti-EGFP (green). ml: molecular layer, gcl: granule cell layer. Scale bars, $50 \mu \mathrm{m}$.

mossy cells (MCs) in the hilus (asterisks), whereas it was absent from doublecortin (DCX)- and CRT-expressing immature neurons in the GCL and GAD67-expressing GABAergic interneurons throughout the DG (Fig. 2d). Together, we conclude that $\mathrm{KI} 198^{\mathrm{Cre}}$ targets mature excitatory neurons in the DG, including GCs and hilar MCs, but not immature neurons, inhibitory interneurons, or nonneuronal cells.

To compare the distribution of $\mathrm{KI} 198^{\mathrm{Cre}}$ cells to $5-\mathrm{HT}_{4} \mathrm{R}$ expressing cells in the hippocampus, we generated Htr4bacTRAP mice where the EGFPL10a transgene was driven by a Htr4 BAC promoter to recapitulate endogenous Htr4 expression (Fig. S2a, b). GFP expression in the hippocampus of Htr4-bacTRAP mice was highly similar to $\mathrm{KI} 198^{\mathrm{Cre}}$ mice, primarily labeling pyramidal cells in the CA fields, and GCs and MCs in the DG (Figs. 2b, d and S2c, d). GFP was not observed in progenitor cells and immature GCs, suggesting a lack of $5-\mathrm{HT}_{4} \mathrm{R}$ in these cells, as seen by others [32]. Htr4-bacTRAP labeled many more cells in the vCA1 and there was a notable lateral-to-medial gradient in the number of cells labeled in $\mathrm{dCA} 3$ and vCA3. This pattern was also seen by Htr4 ISH (Fig. S2a and the Allen Brain Atlas, www.brain-map.org). Interestingly, $\mathrm{KI} 198^{\mathrm{Cre}}$ expression had an opposite CA3 gradient with denser labeling near the DG and fewer cells approaching CA2 (Fig. 2a, c). Since KI198 ${ }^{\mathrm{Cre}}$ reflects endogenous Htr4 expression in the DG, crossing this line with $\mathrm{Htr}_{4}{ }^{\text {Floxed }}$ mice results in nonfunctional $5-\mathrm{HT}_{4} \mathrm{R}$ throughout the DG. The incomplete overlap in the CA fields suggests only partial deletion of $5-\mathrm{HT}_{4} \mathrm{R}$ function in this region. Notably GFP was visible in many other cells throughout the brain in the Htr4-bacTRAP mice, including cortex, hypothalamus, midbrain, and most cells in the ventromedial forebrain, contrasting with the restricted $\mathrm{KI}_{198}{ }^{\mathrm{Cre}}$ expression (Fig. S2a, b).

\section{The effect of hippocampus specific loss of $5-\mathrm{HT}_{4} \mathrm{R}$ on mood and anxiety related behaviors}

Given the direct role of serotonin in the regulation of mood [33] and that $5-\mathrm{HT}_{4} \mathrm{R}$ has been shown to mediate $\mathrm{AD}$ responses [16], we investigated the impact of the conditional ablation of $5-\mathrm{HT}_{4} \mathrm{R}$ from hippocampus on moodrelated behaviors. We first employed the tail suspension (TST) and forced swim tests (FST) which assess responses to an acute, inescapable stressor as a measure of behavioral despair [34-36]. Immobility was decreased in cKO mice compared to WT littermates in both TST and FST (Fig. 3a, b), indicating reduced despair-like behavior and mimicking an AD-like response. These results were not due to a general hyperactivity of the cKOs since they did not differ from WTs in locomotor behavior in an open field arena (Fig. S3e).

The splash test and sucrose consumption are commonly used as indicators of hedonic state in depression models and rely on the animal's motivation for self-grooming and the rewarding properties of a sweet, palatable sucrose solution, respectively [37-39]. In the splash test, cKO mice spent more time grooming following the application of a sucrose solution compared to WT littermates, mimicking the effect of antidepressant administration (Fig. 3c). During the sucrose consumption, both cKO and WT mice drank approximately 5-10-fold more sucrose than water each day over the three-day test (Fig. S3a, b), implying no difference in hedonic capacity between genotypes. Interestingly, cKO mice consumed cumulatively more sucrose after $72 \mathrm{hrs}$ compared to WT. This result was unlikely due to a change in caloric need since body weight was unaltered in the cKOs (Fig. S3c). The significance of the increased sucrose consumption is difficult to interpret given the strong sucrose preference exhibited by both groups but may reflect a subtle rise in pleasure-seeking drive. Together with the FST and TST results, these data indicate that $\mathrm{cKO}$ mice displayed reduced behavioral despair and increased hedonic drive, strongly mimicking an AD-like response.

As anxiety is closely associated with mood disorders and $\mathrm{AD}$ treatment, and has been linked to hippocampal and $5-\mathrm{HT}_{4} \mathrm{R}$ function [17, 40], we next assessed how hippocampus-specific loss of 5- $\mathrm{HT}_{4} \mathrm{R}$ affected a variety of anxiety-related behaviors. The open-field test (OF), elevated plus maze (EPM) and novelty suppressed feeding (NSF) paradigms all rely on mice having an innate aversion to well-lit, open spaces while NSF adds the conflict of engaging in feeding behavior in a novel environment [41-44]. In the OF, cKO mice spent less time in the center of the arena 
a

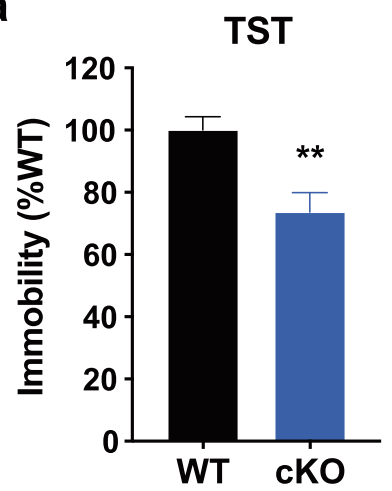

d

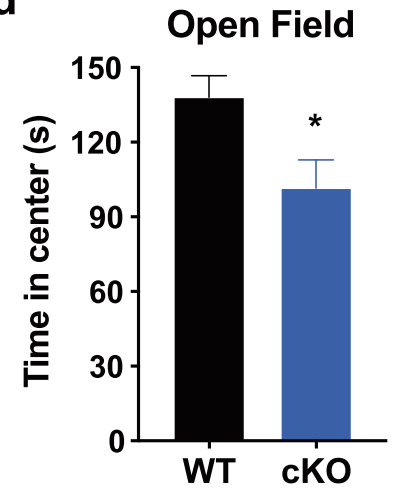

b

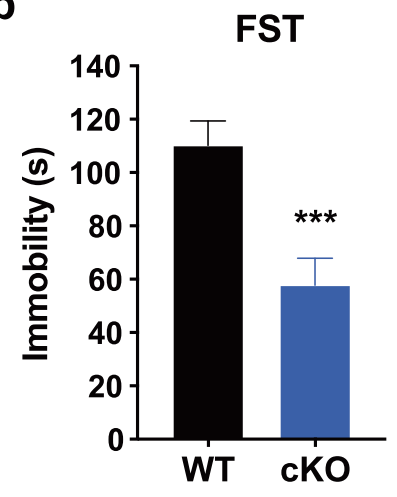

e

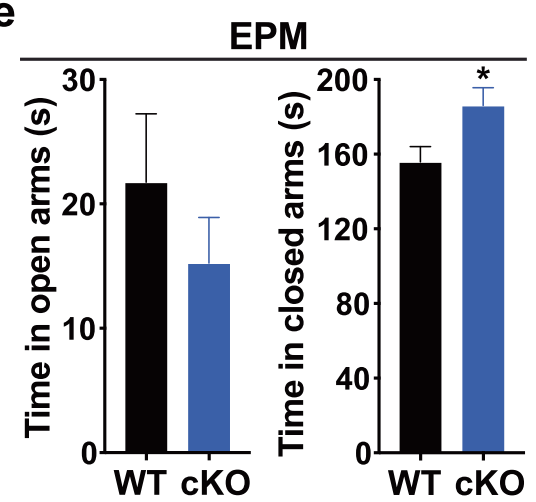

C

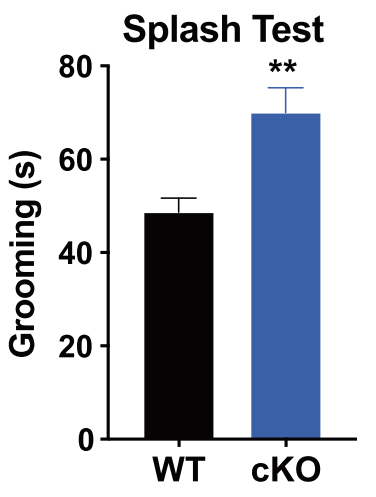

f

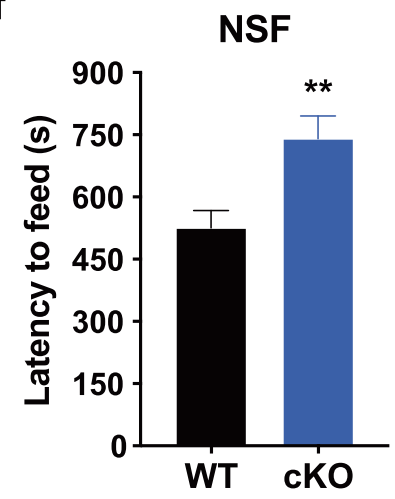

g

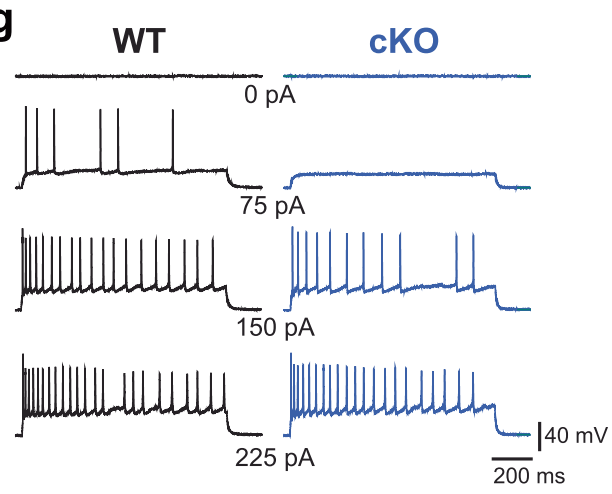

Fig. 3 cKO mice exhibit altered affective behaviors and reduced firing in VDG granule cells. a Quantification of the time spent immobile in the tail suspension test (TST) in cKO mice (cKO, blue) and Cre-negative littermates (WT, black). ${ }^{*} p=0.0012, \mathrm{n}_{\mathrm{WT}}=19$, $\mathrm{n}_{\mathrm{cKO}}=16$. b Quantification of the time spent immobile in the forced swim test (FST) for each genotype. $* * * p=0.0005, \mathrm{n}_{\mathrm{WT}}=19, \mathrm{n}_{\mathrm{cKO}}=$ 16. c Quantification of grooming time in the splash test for each genotype. ${ }^{* *} p=0.001, \mathrm{n}_{\mathrm{WT}}=19, \mathrm{n}_{\mathrm{cKO}}=16$. $\mathbf{d}$ Mean time spent in the center in the open field (OF) for each genotype. ${ }^{*} p=0.0139, \mathrm{n}_{\mathrm{WT}}=$ $19, \mathrm{n}_{\mathrm{cKO}}=17$. e Quantification of the time spent in the open (left) and closed (right) arms in the elevated plus maze (EPM). ${ }^{*} p=0.0239$,

during the initial 10 min compared to WT littermates while showing similar overall locomotor activity (Figs. 3d and S3d, e). The latency to enter the center also differed between groups (WT: $5.7 \pm 2.2 \mathrm{~s}$ vs. KO: $20.4 \pm 5.3 \mathrm{~s}$; Mann-Whitney test: $U=78, p=0.006$ ) while total distance travelled in the center during the first 10 min showed a similar trend, although it did not reach statistical significance (WT: $661.6 \mathrm{~cm} \pm 47.9$ vs. KO: $538.8 \mathrm{~cm} \pm 54.0$; unpaired $t$-test: $\mathrm{t}(35)=1.706, p=0.097)$. In the EPM, the cKOs spent more time in the closed arms compared to WT 
(Fig. 3e). Although the time spent in the open arms did not differ between genotypes, the cKOs displayed a trend towards higher velocity in EPM compared to WT (Fig. S3f) suggesting that higher exploratory activity of cKO mice was not accompanied by more exploration of the open arms. The cKO mice also displayed a greater latency to feed in NSF (Fig. 3f) yet consumed more food on average when placed back into their familiar home cages following NSF (Fig. S3g), conveying that the lack of motivation to feed was not the source of their prolonged latency. Together, these conflict-based behavioral analyses indicate that cKO mice have an anxiety-like phenotype.

We also tested behaviors that may be affected by anxiety levels such as social interaction and acoustic startle response (ASR). Mice were tested in the three-chamber social interaction test to measure sociability since a reduced amount of time spent interacting with a novel conspecific has been associated with abnormal anxiety-like behaviors [45]. We observed that cKO mice interacted less with a novel mouse compared to WT (Fig. S3h). Enhanced startle response has also been linked to increased anxiety and its physiological features [46, 47] while blunted startle was observed in patients with anhedonia [48-50]. We found that ASR was significantly enhanced in cKO mice compared to WT (Fig. S3i, j). On the other hand, the pre-pulse inhibition (PPI), the suppression of ASR when a startling stimulus is preceded by an immediate, weaker pre-stimulus, was not altered (Fig. S3k). Together, these anxiety-regulated responses reflect the anxiogenic phenotype observed in the cKOs.

\section{Loss of $5-\mathrm{HT}_{4} \mathrm{R}$ reduces the excitability of dentate gyrus granule cells}

Activation of $5-\mathrm{HT}_{4} \mathrm{R}$ leads to depolarizing currents via second messenger mechanisms in excitatory cells of the hippocampus [11], including DG GCs (Fig.1d). To test the electrophysiological consequences of functional loss of $5-\mathrm{HT}_{4} \mathrm{R}$, we performed whole-cell current clamp recordings from vDG GCs in acute hippocampal slices from WT and cKO mice. We found that the firing frequency of GCs was significantly reduced in cKO slices compared to WT (Fig. 3g, h). In addition, rheobase, the amount of current necessary to be injected to elicit an action potential, was larger in GCs from cKO mice (Fig. 3i). On the contrary, there was no difference in the properties of single-action potentials between genotypes, including threshold, amplitude, half-amplitude width, and fast after-hyperpolarization as well as the input resistance and slow after-hyperpolarization (Fig. S4a-g). These data show that the loss of $5-\mathrm{HT}_{4} \mathrm{R}$ leads to specific physiological changes resulting in a reduced excitability in DG GCs.
Molecular adaptations in the vDG of cKO mice highlight cellular and functional roles for $5-\mathrm{HT}_{4} \mathrm{R}$

We next investigated global differences in gene expression that occurred following the deletion of hippocampal $5-\mathrm{HT}_{4} \mathrm{R}$ to identify molecular mechanisms that may underlie the behavioral and electrophysiological phenotypes observed in cKO mice. We focused on the ventral DG since nearly all $5-\mathrm{HT}_{4} \mathrm{R}$ expressing cells in the DG, but not CA fields, are targeted by the $\mathrm{KI} 198^{\mathrm{Cre}}$ line (Fig. 2a-c), and there is a strong link between ventral hippocampus and the regulation of depression and anxiety [27]. The translating ribosome affinity purification (TRAP) method [51, 52] was used to isolate cell typespecific transcripts by expressing the EGFPL10a TRAP transgene in WT and $\mathrm{cKO} \mathrm{KI}_{198^{\mathrm{Cre}}}$ cells by crossing $\mathrm{KI} 198^{\mathrm{Cre}}$ with Rosa26 $6^{\mathrm{fsTRAP}}$, and $\mathrm{KI} 198^{\mathrm{Cre}}:: \mathrm{Htr} 4^{\text {Floxed }}$ with Rosa26 $6^{\text {fsTRAP }}:: \mathrm{Htr}_{4} 4^{\text {Floxed }}$ mice, respectively (Fig. 4a). Polysome-bound mRNAs were extracted following antiEGFP immunoprecipitations (IP) on vDG homogenates and analyzed by RNA-seq alongside mRNAs extracted from whole tissue (input) (Fig. S5a). The quality of dissection was confirmed by qRT-PCR which showed that markers for DG $(D s p)$ and vDG (Trhr) were highly expressed in vDG inputs but markers for CA fields (Tyro) and dDG $(L c t)$ were not (Fig. S5b-c). Visualization of RNA-seq reads mapped to the Htr4 locus confirmed the deletion of exon 5 in cKO tissue (Fig. 4b), although overall expression of Htr4 was increased in cKO TRAP mRNA compared to WT, likely reflecting an attempt by the cells to compensate for the non-functional protein (Fig. 4c). There did not appear to be a broader compensation in 5-HT signaling since there was no difference in the expression of other 5-HT receptor transcripts between genotypes (Fig. 4c). Consistent with previous reports of the distribution of 5-HT receptors in the DG [29], the receptors with highest expression in the vDG TRAP were Htrla, Htr2a, Htr4, and Htr5a.

A direct comparison of gene expression between TRAP mRNA (IP) and whole tissue mRNA (input) revealed a substantial depletion of markers for interneurons, progenitors, and other non-neuronal cells in the TRAP data set (Fig. S5d-f), consistent with our immunohistology showing the $\mathrm{KI} 198^{\mathrm{Cre}}$ line primarily labels mature GCs and hilar MCs in the DG (Fig. 2c). While markers for GCs were highly expressed in TRAP mRNA, their underwhelming levels of enrichment in IP over input, compared to the depletions of markers of cells not labeled by $\mathrm{KI}_{1} 198^{\mathrm{Cre}}$ (Fig. S5e, f), were likely because most of the transcripts in the input were from mature GCs since they constitute the vast majority of all cells in the DG. TRAP IPs from WT and cKO mice showed a similar distribution of marker genes and IP-enriched transcripts (Figs. S5e, f and S6a) indicating 
a

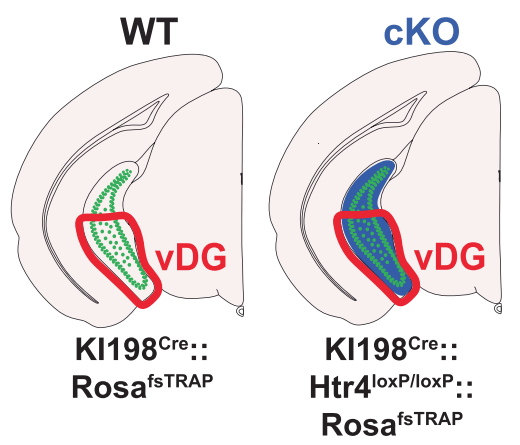

b

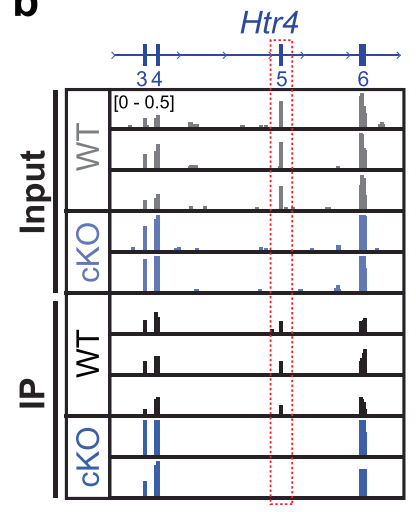

C

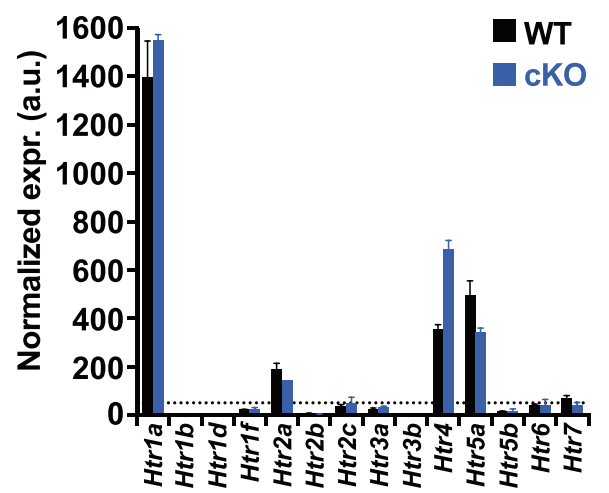

d

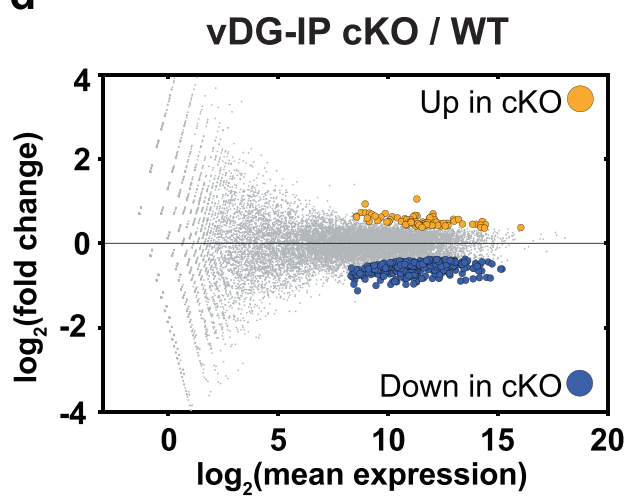

e

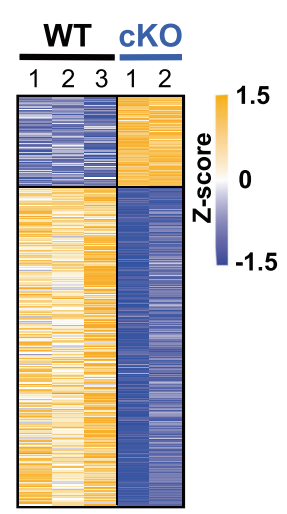

f

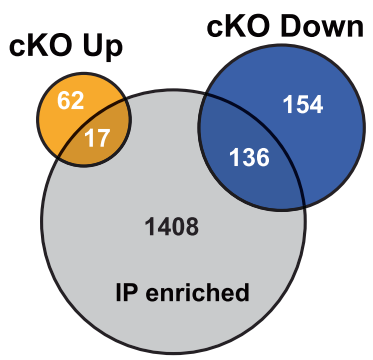

g

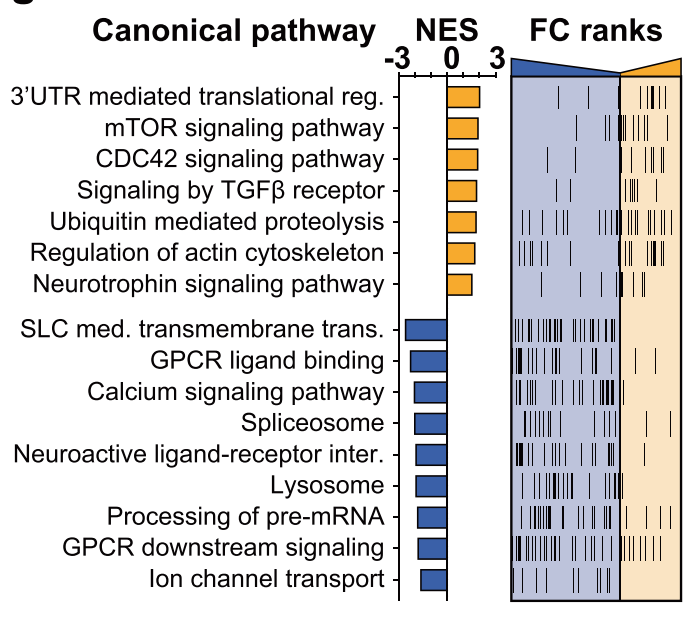

h

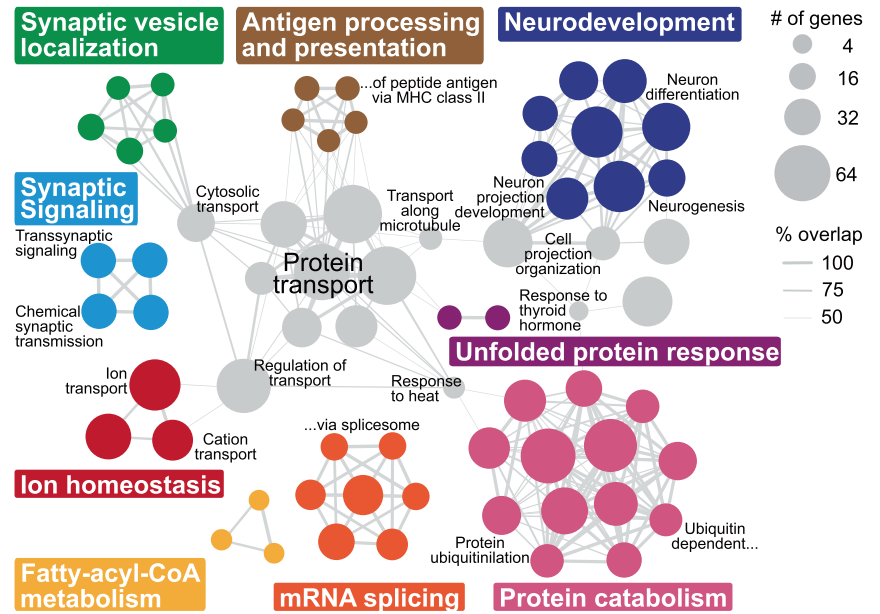

Fig. 4 TRAP profiling of vDG neurons in the absence of $5-H T_{4} R$. a Schematic depicting the cell types targeted for TRAP. Green represents EGFPL10a expressing cells and blue indicates conditional $5-\mathrm{HT}_{4} \mathrm{R}$ deletion. The area dissected is outlined in red. b Browser view of mapped reads showing the lack of expression of $\mathrm{Htr} 4$ exon 5 in IP and input samples in the cKO. c Bar graph of normalized expression values (mean \pm SEM) of all 5-HT receptors (Htrs) in IP samples. Dashed line is drawn at normalized expr. $=50$. Only Htr4 has FDR $<$ 0.1. d MA-plot highlighting differentially expressed (DE) genes (FDR $<0.1)$ between the cKO and WT TRAP mRNA. Complete list of IP $\mathrm{DE}$ genes can be found in Table S1. e Heatmap visualization of DE genes between genotypes. $\mathbf{f}$ Venn diagram showing the overlap of upand down-regulated DE genes from e with genes enriched in the KI198 ${ }^{\mathrm{Cre}}$-expressing cells (IP enriched, Table S2). g Summary of gene set enrichment analysis (GSEA) performed on the fold change (FC)ranked gene list $(p<0.05)$ between $\mathrm{cKO}$ and WT IP data sets. The normalized enrichment score (NES) shows the direction of enrichment in the cKO and FC-ranks are arranged from down-regulated (blue) at left to up-regulated (yellow) at right. Complete list of pathways can be found in Table S3. h Summary of gene ontology (GO) analysis of DE from e. All categories shown have FDR $<0.01$, full analysis is provided in Table S4. 
that the mutant allele did not noticeably alter cellular identity.

Differential expression analysis of TRAP mRNA identified 80 upregulated and 290 downregulated genes in cKOs compared to WT (Fig. 4d). Heatmap visualization based on normalized expression values showed that the significant gene expression differences between genotypes were consistent across all replicates (Fig. 4e). Over $40 \%$ of the differentially expressed (DE) genes (17 up- and 136 downregulated) were enriched in the IP of KI $198^{\mathrm{Cre}}$ cells (Fig. 4f), illustrating a strong cell type-specific adaptation. Quantitative RT-PCR (qRT-PCR) of selected genes confirmed these results showing that Cox8a, Trib2, Trmt112, and $W b s c r 22$ were enriched while $C d h 10, P i k 3 r 3, R d x$, and Ryr2 were depleted in cKOs at similar levels to RNA-seq data (Fig. S5g). To gain a general understanding of the gene pathways dysregulated in the cKOs, we performed gene set enrichment analysis (GSEA) on a ranked list of genes differing between WT and cKO samples (Fig. 4g). We found positive enrichment in signaling pathways linked to translation, neuroplasticity, and cytoskeletal regulation, including mTOR, CDC42, TGF $\beta$, neurotrophin signaling, and regulation of actin cytoskeleton, all of which have been shown to be regulated by $\mathrm{AD}$ treatment. Interestingly, there was an upregulation in ubiquitin proteolysis and 3'UTR mediated translation, and a downregulation in pre-mRNA processing, implying a possible response to the handling of the mutant $\mathrm{Htr} 4$ transcript and $5-\mathrm{HT}_{4} \mathrm{R}$ protein. We found negative enrichment in pathways related to $5-\mathrm{HT}_{4} \mathrm{R}$ function including GPCR ligand binding, calcium signaling, neuroactive ligand-receptor interaction, and GPCR downstream signaling, paralleled by decreased expression of genes involved in cAMP signaling (Figs. 4g and S6b). In addition, there was a downregulation in pre-mRNA processing and transmembrane transport of various classes of ions (Figs. $4 \mathrm{~g}$ and S6c). Functional annotation analysis focused on significantly DE genes between genotypes showed alterations in processes underlying neuronal function including synaptic vesicle localization, neuron development, synaptic signaling, and ion homeostasis, while unfolded protein response and protein catabolism imply a change in proteostasis (Fig. 4h). Together, our molecular profiling of the vDG from $\mathrm{cKO}$ and WT mice identified substantial transcriptional changes in the absence of $5-\mathrm{HT}_{4} \mathrm{R}$ that are related to neuronal function and intracellular $5-\mathrm{HT}_{4} \mathrm{R}$ receptor signaling.

\section{The ablation of $5-\mathrm{HT}_{4} \mathrm{R}$ resulted in enhanced adult neurogenesis in the vDG}

Up to this point, we have investigated the effects of $5-\mathrm{HT}_{4} \mathrm{R}$ loss on the intrinsic molecular and electrophysiological properties Htr4-expressing cells. To ask how these adaptations impacted the overall cellular environment within the DG, we utilized the whole tissue input mRNA since it was enriched with transcripts expressed in non-neuronal cells, progenitors, and interneurons (Fig. S5e), allowing us to examine broad molecular responses in non-Htr4-expressing cells. DE analysis between WT and cKO input tissue revealed a robust molecular response (625 DE genes) in the whole vDG and a relatively small response in the whole dDG (179 genes) (Figs. 5a and S7a). Only 25 genes were shared between regions (Fig. S7b, c). Functional annotation of DE genes revealed remarkably distinct cellular adaptations between the two regions. Processes related to neural function and plasticity, including neurogenesis, neuron development and differentiation, synaptic signaling, ion transport, and homeostasis, and regulation of action potential were uniquely enriched in the whole vDG mRNA but not dDG (Figs. 5b and S7d). The genes altered in the whole dDG mRNA were primarily related to protein and RNA processing. Furthermore, disease-gene association analysis of DE genes in the whole vDG also showed significant enrichment for a variety of diseases, including affective disorders such as depressive, bipolar, and anxiety disorders, along with other psychiatric disorders (Fig. S7e). No significant disease-gene associations were found in the dDG. In addition, 430 genes were uniquely altered in the vDG input but not TRAP IPs (Fig. 5c) reflecting changes that occurred primarily in non-Htr4-expressing cells. These genes were predominantly related to neurogenesis and neurodevelopment (Fig. 5d) whereas many genes unique to the IPs reflected intrinsic cellular processes such as ion homeostasis and transport, synaptic signaling, and protein processing (Figs. 5e, f and S6b).

Our genome-wide transcriptional analysis revealed significant alterations in gene expression related to neurogenesis and development in the whole vDG and an upregulation of factors known to promote neurogenesis and plasticity specifically in the KI $198^{\text {Cre }}$ cells (Figs. 4e, f and $5 \mathrm{~b}, \mathrm{~d})$. This is particularly interesting given that the cKOs exhibit AD-like behavioral responses and the link between adult neurogenesis of DG GCs and SSRI antidepressants [27]. We therefore examined whether we could detect any change in hippocampal neurogenesis in the cKOs by quantifying the number of doublecortinpositive $(\mathrm{DCX}+)$ immature neurons along the dorsoventral axis of the subgranular zone (SGZ) and GC layer of the DG in WT and cKOs (Figs. 5e and S7f). There was a $67 \%$ increase in the number of DCX + neurons in the vDG of cKO mice compared to WT littermates, while no difference in the number of DCX + neurons was detected in the dDG or intermediate DG (Fig. 5f). These results suggest that loss of functional $5-\mathrm{HT}_{4} \mathrm{R}$ led to an increase in immature GCs in the vDG, which likely occurred 
Fig. 5 Loss of $5-\mathrm{HT}_{4} \mathrm{R}$ led to changes in neurogenesisrelated genes and increased number of immature neurons in the vDG. a MA-plots indicating differentially expressed (DE) genes (FDR < 0.05 ) between $\mathrm{cKO}$ and WT mRNA from whole dDG (top) and vDG (bottom). Complete lists can be found in Tables S5 and S6. b Comparison of significantly enriched gene ontology (GO) terms among whole dDG and vDG DE genes from a. c Venn diagram comparing DE transcripts shared and unique to vDG TRAP (dark blue) and whole vDG tissue (light blue) samples. d Top ten GO terms enriched in the whole vDG-specific gene list from c. Terms related to neurogenic tone are in bold. Complete lists can be found in Tables S7 and S8. e Representative images of antiDCX immunofluorescence in coronal sections through $\mathrm{dDG}$ and vDG from cKO and WT mice. Arrowheads indicate DCX + cells. DAPI is shown in blue. Scale bar, $150 \mu \mathrm{m}$.

f Quantification (mean \pm SEM) of DCX + cells per granule cell layer area in the dorsal (dDG), intermediate (iDG), and ventral (vDG) DG. Two-way ANOVA: genotype $\times$ region interaction, $\mathrm{F}$ $(2,24)=6.328, p=0.0062$ followed by post hoc Fisher's LSD test, ${ }^{* *} p=0.002 . n=5$ per genotype.
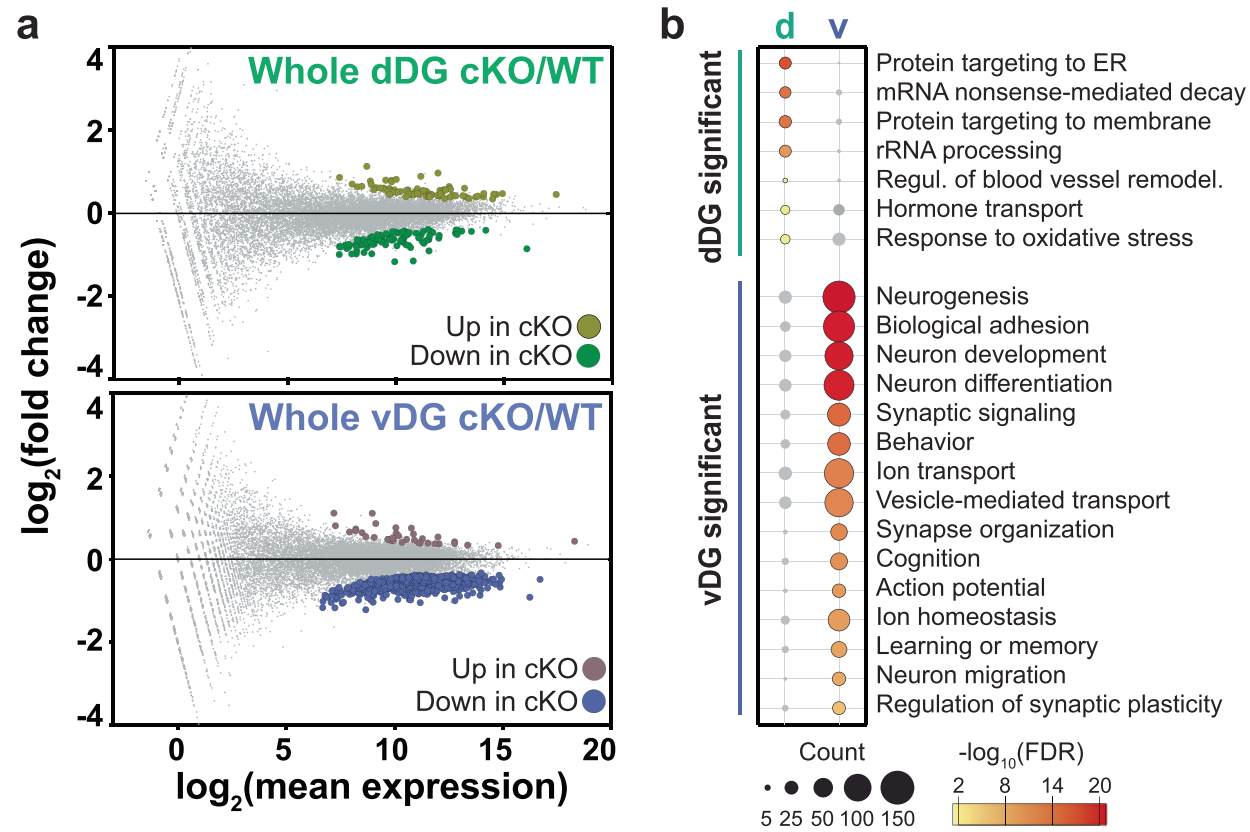

C

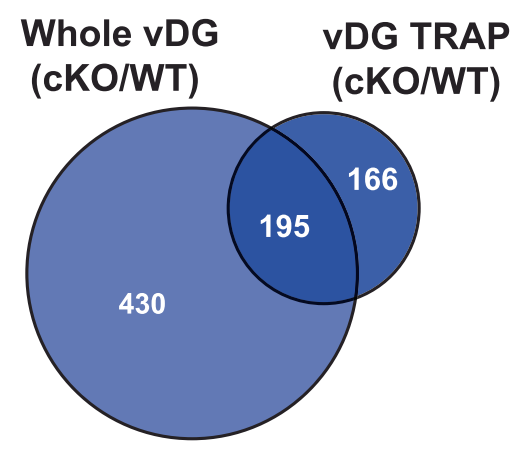

d

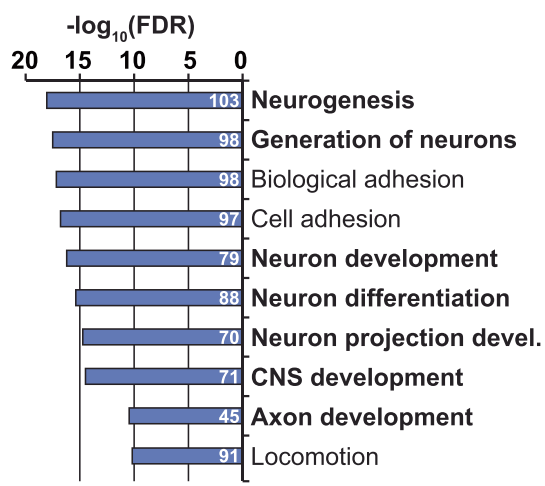

e

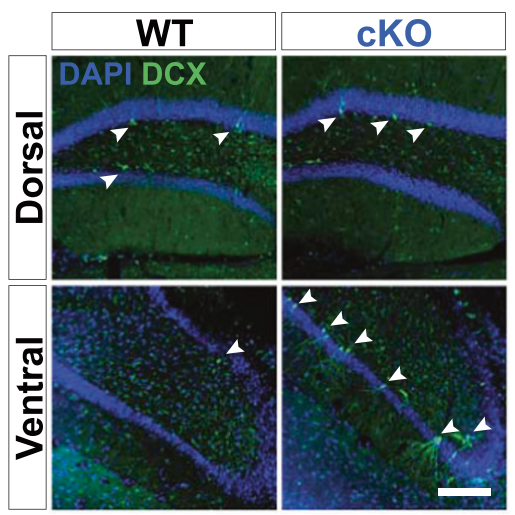

f

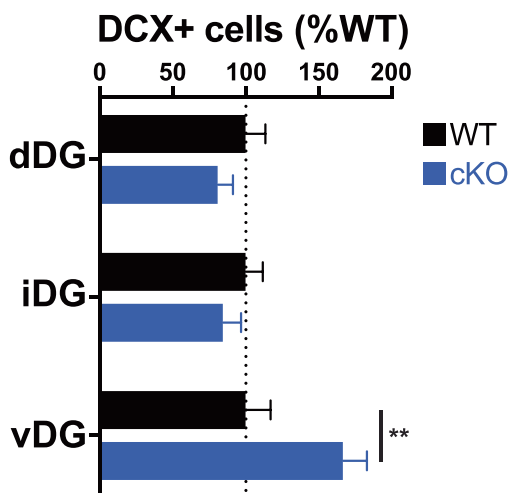

through a non-cell-autonomous manner since $\mathrm{KI} 198^{\mathrm{Cre}}$ does not target progenitor cells or immature neurons. Together, these data demonstrate a remarkable amount of region-specific cellular and molecular adaptations along the dorsoventral axis of DG in response to loss of 5-HT $\mathrm{HT}_{4}$ function.

\section{Discussion}

In the current study, we generated conditional $5-\mathrm{HT}_{4} \mathrm{R}$ knockout mice to examine the role of this receptor in discrete cell populations in the hippocampal formation at behavioral, cellular, and molecular levels. Cre-mediated 
recombination resulted in a truncated and unstable protein as demonstrated by the absence of cAMP activation or an electrophysiological response to $5-\mathrm{HT}_{4} \mathrm{R}$ agonists and a downregulation of $5-\mathrm{HT}_{4} \mathrm{R}$-related signaling pathways in cells harboring the mutant allele. The loss of $5-\mathrm{HT}_{4} \mathrm{R}$ primarily from excitatory neurons in the DG and hilus led to AD-like performance in behavioral tests of despair and anhedonia, and elevated anxiety. DG GCs were less excitable and showed altered expression of genes related to GPCR function, ion transport, and neuroplasticity in the absence of $5-\mathrm{HT}_{4} \mathrm{R}$. In addition, cKO mice showed increased number of immature GCs in the vDG but not $\mathrm{dDG}$, indicating regional differences in adaptions to 5- $\mathrm{HT}_{4} \mathrm{R}$ loss in the local environment along the dorsoventral axis. Taken together, these results strongly suggest that the congenital removal of functional $5-\mathrm{HT}_{4} \mathrm{R}$ from excitatory cells in the DG leads to cellular and molecular adaptations that mimic chronic AD treatment and offers insight into the modulation of mood by hippocampal circuits.

Decreased functionality of hippocampal $5-\mathrm{HT}_{4}$ receptors is consistent with reports describing cellular responses to antidepressants. Chronic SSRI treatment has been shown to reduce the density of $5-\mathrm{HT}_{4} \mathrm{R}$ binding and decrease $5-\mathrm{HT}_{4} \mathrm{R}$-dependent cAMP signaling and postsynaptic excitability in hippocampal pyramidal cells in rats [53]. Moreover, short-term treatment with the partial 5- $\mathrm{HT}_{4} \mathrm{R}$ agonist, $\mathrm{RS} 67333$, led to $5-\mathrm{HT}_{4} \mathrm{R}$ desensitization in hippocampus [18]. These findings together with our results highlight a multifaceted role for $5-\mathrm{HT}_{4} \mathrm{R}$ in the regulation of hippocampal circuits underlying mood. $5-\mathrm{HT}_{4} \mathrm{R}$ is expressed in many limbic structures besides the hippocampus including prefrontal cortex, ventral striatum, and amygdala [19] and it is generally thought that $5-\mathrm{HT}_{4} \mathrm{R}$ activation is therapeutic. Indeed, the mPFC has been implicated as a site mediating the fast-acting anxiolytic and/or antidepressant effects since RS67333 [15, 54] and the overexpression of $5-\mathrm{HT}_{4} \mathrm{R}$ specifically in the mPFC led to AD-like behavior [55]. We previously found that chronic SSRI administration led to increased Htr4 expression in corticostriatal neurons in sensorimotor cortex [5], although it does not appear to underlie SSRImediated changes in 5-HT responses in those cells [56]. The lack of impact of constitutive deletion of $5-\mathrm{HT}_{4} \mathrm{R}$ on baseline mood [21] further attests to the complex interplay between different circuit components that express the receptor. We cannot rule out that $5-\mathrm{HT}_{4} \mathrm{R}$ deletion from the subset of CA pyramidal cells that overlap in Htr4 and $\mathrm{KI} 198^{\mathrm{Cre}}$ expression or the scattered $\mathrm{KI} 198^{\mathrm{Cre}}$-expressing cells in the ventromedial forebrain and islands of Calleja contributes to the observed behavioral phenotypes, given their role in mood $[57,58]$. However, the nearly complete overlap of $\mathrm{KI}_{198}{ }^{\mathrm{Cre}}$ and Htr4 in DG and the discernable molecular and electrophysiological adaptations in the
vDG GCs of cKO mice strongly support a fundamental role for hippocampal 5- $\mathrm{HT}_{4} \mathrm{R}$.

The reduced electrophysiological excitability of DG GCs in the absence of $5-\mathrm{HT}_{4} \mathrm{R}$ was either directly due to a deficiency of $5-\mathrm{HT}_{4} \mathrm{R}$ signaling or a result of long-term cellular adaptations in the absence of the receptor. $5-\mathrm{HT}_{4} \mathrm{R}$ has been shown to contribute to the excitability of pyramidal cells through PKA-mediated closure of $\mathrm{Ca}^{2+}$-activated $\mathrm{K}^{+}$channels underlying sAHP current [11, 59-61], however, we did not see any change in slow or fast AHPs in the cKOs. A direct coupling to both voltage-sensitive calcium channels [62] and the extracellular signal-regulated kinase pathway [63], both of which are known to modulate neuronal function $[64,65]$, has also been proposed for 5$\mathrm{HT}_{4} \mathrm{R}$ function. The TRAP data revealed a dysregulation of $\mathrm{Ca}^{2+}$ signaling, ion homeostasis, and/or ion channel expression in the cKOs, although more work is needed to understand the significance of these changes on GC excitability.

The decreased excitability of the vDG GCs may have directly contributed to the AD-like phenotype of the cKOs. Growing evidence supports a link between suppressed activity of DG GCs and AD-like behavior. Decreased excitability of vDG GCs through local GABAergic inhibition produces behavioral $\mathrm{AD}$ action [66], and indirect inhibition of mature GCs of the vDG by immature GCs, or by chemogenetic methods promotes resilience to stress [67]. In addition, SSRI-mediated inhibition of GCs through $5-\mathrm{HT}_{1 \mathrm{~A}} \mathrm{R}$ is necessary for $\mathrm{AD}$ responses in preclinical models [68]. Blockade of GC-CA3 glutamate release and NMDA receptor activity reduces behavioral despair [69], and the therapeutic effects of antidepressants and $5-\mathrm{HT}_{4} \mathrm{R}$ agonists in rodents are dependent on the tonic inhibition of CA3 pyramidal cells via the activation of $5-\mathrm{HT}_{1 \mathrm{~A}}$ receptors [16]. Finally, chronic AD administration attenuated excitatory physiological effects of 5- $\mathrm{HT}_{4} \mathrm{R}$ throughout the hippocampal circuit $[53,70]$. It is possible that the $5-\mathrm{HT}_{4} \mathrm{R}$ loss led to a shift in the balance of excitatory and inhibitory 5-HT signaling in DG which contributed to the AD-like phenotype of the cKOs. Both 5- $\mathrm{HT}_{4}$ and $5-\mathrm{HT}_{1 \mathrm{~A}}$ receptors are highly expressed in DG GCs and cooperate to mediate cellular responses to 5-HT despite activating opposing second messenger pathways and electrophysiological properties [9, 68]. The broad downregulation of cAMPrelated genes and GPCR signaling detected in the cKO TRAP data support this idea.

The anxiogenic phenotype of the $5-\mathrm{HT}_{4} \mathrm{R}$ cKO mice reinforces a role for hippocampal $5-\mathrm{HT}_{4} \mathrm{R}$ in directly moderating anxiety, possibly though modulating the excitability of vDG GCs. Acute optogenetic activation of vDG GCs was shown to suppress innate anxiety, although increased anxiety was not observed when vDG GCs were acutely inhibited [40]. Long-term inhibition of GCs due to 
chronic loss of 5- $\mathrm{HT}_{4} \mathrm{R}$ functionality in the cKOs may have amplified this effect in our study. Systemic administration of pharmacological agents have also demonstrated robust anxiolytic properties of $5-\mathrm{HT}_{4} \mathrm{R}$ agonists while $5-\mathrm{HT}_{4} \mathrm{R}$ antagonists blocked the anxiolytic effects of diazepam and SSRIs [17, 19, 71]. Discrete subsets of vCA1 projection neurons also control anxiety-related behaviors depending on their postsynaptic targets [72, 73], indicating a complexity of cell-specific mechanisms even within the hippocampal circuit. Although $\mathrm{KI} 198^{\mathrm{Cre}}$ was absent from vCA1, likely preserving $5-\mathrm{HT}_{4} \mathrm{R}$ function in most $\mathrm{vCA} 1$ pyramidal cells in the cKOs, reduced activity of vDG GCs probably had a significant impact on the trisynaptic hippocampal circuit and vCA1 outputs.

5- $\mathrm{HT}_{4} \mathrm{R}$ deletion also had a palpable effect on molecular and cellular neuroplasticity in the vDG. Cell type-specific molecular profiling of vDG GCs with TRAP provided evidence for an alteration in the neuroadaptive state of the cells highlighted by a change in genes linked to processes such as neuronal development, differentiation, and synaptic signaling. These pathways are differentially regulated in the hippocampus with $\mathrm{AD}$ treatment, deep brain stimulation, and exposure to stress [7, 8, 74-77] and likely underlie the changes in synaptic plasticity, spine density, and dendritic architecture of hippocampal neurons observed after $\mathrm{AD}$ administration [3, 78, 79]. The molecular adaptations in GCs were accompanied by an increase in the number of immature GCs selectively in the vDG in the cKOs. Adult hippocampal neurogenesis mediates some of the behavioral effects of SSRI treatments and responses to stress $[37,67,80]$ but does not produce AD-like behavior on its own [81]. The absence of $5-\mathrm{HT}_{4} \mathrm{R}$ and Cre from neural progenitors and immature GCs suggests the enhanced neurogenesis was a response to changes in the local environment, although based on our results we cannot definitively conclude whether the increase in immature GCs was due to changes in proliferation, survival, or maturation. We speculate that the cKOs have a deficit in maturation given the dysregulation of genes related to neurodevelopment and differentiation together with previous reports showing no change in baseline proliferation in global KOs [32] and the promotion of survival after pharmacological stimulation of $5-\mathrm{HT}_{4} \mathrm{R}$ in hippocampus [17]. The lack of change in neurogenesis in the $\mathrm{dDG}$ underscores the functional divergence of the DG along the dorsoventral axis [27, 82] and the regional specificity of $5-\mathrm{HT}_{4} \mathrm{R}$ function. A similar anatomical discrepancy in neurogenesis was observed in patients and mice following chronic SSRI treatment $[83,84]$ and the ablation of adult-born GCs in the vDG, but not dDG attenuated some of the behavioral responses to AD treatment, stress, and chronic pain [85, 86].

The present study begins to refine a role for $5-\mathrm{HT}_{4} \mathrm{R}$ in a key circuit that mediates mood and anxiety and reinforces the complexity of neuromodulatory signaling in arbitrating emotion. This notion is underscored by the fact that the ADlike phenotype following the cell type-specific conditional deletion of $5-\mathrm{HT}_{4} \mathrm{R}$ was accompanied by an increase in anxiety. SSRIs and other AD drugs are commonly used to treat anxiety disorders so the anxiogenic behavior of the $\mathrm{KI}_{198}{ }^{\mathrm{Cre}}$ 5- $\mathrm{HT}_{4} \mathrm{R}$ cKO mice indicates a dissociation between the mechanism underlying these behaviors. Indeed, antidepressants can promote suicidality, anxiety, and nervousness, posing clinical concerns, and acute and chronic SSRI treatment in rodents can induce anxiety-like behaviors depending on the baseline anxiety/stress/depression levels, strain, age, dose, and delivery method of AD treatment [8790]. Our data justify further inquiry to determine if these phenomena are moderated by a direct result of chronic disengagement of hippocampal $5-\mathrm{HT}_{4} \mathrm{R}$ or due to an indirect effect, such as compensatory cellular and circuitlevel adaptations resulting from non-functional receptor throughout development. Such observations and the widespread impact of the therapeutic targeting of broad neuromodulatory systems underscore the need to tease apart regional, temporal, and cell type-specific mechanisms to develop better drugs with diminished side effects.

\section{Materials and methods}

\section{Animals}

All procedures involving animals were approved by The Rockefeller University Institutional Animal Care and Use Committee and were in accordance with National Institutes of Health guidelines. KI198 Cre (Drd3-Cre KI198) mice were generated by the GENSAT Project [30] and were purchased from the Mutant Mouse Regional Resource Center (MMRRC) Repository (Stock \#031741-UCD). Rosa26 ${ }^{\text {fsTRAP }}$ mice were purchased from the Jackson Laboratories (Stock \#022367). Htr $4^{\text {Floxed }}$ and Htr4-bacTRAP mice were generated as described in Supplementary Methods. All animals were bred on a C57BL/6 J background, group-housed, maintained on a 12-h light-dark cycle at The Rockefeller University, and given ad libitum access to food and water. Animals used in the study were male, except for RNA sequencing experiments for which samples from male and female mice were pooled.

\section{Behavior}

Behavioral tests were performed on male mice from 8 weeks to 4 months of age. For each test, mice were agematched, and controls consisted of Cre-negative littermates. For each test, mouse order was randomized, and the experimenter was blinded to genotype during the tests and data analyses. All tests were performed within the light 
period of the light-dark cycle unless otherwise noted. The number of animals per group $(n)$ and the statistical analyses are reported in the figure legends. All behavior tests were performed using established, published protocols. See Supplementary Methods for details.

\section{Total RNA isolation and quantitative RT-PCR (qRT- PCR)}

Total RNA was isolated from dissected tissue using RNeasy Micro Kit (Qiagen, Germantown, MD). cDNA samples were generated using qScript cDNA SuperMix (QuantaBio, Beverly, MA). All qRT-PCR experiments were performed on the LightCycler 480 System (Roche Diagnostics, Indianapolis, IN), using TaqMan assays (Applied Biosystems, Foster City, CA). Three technical triplicates were run, and the mean $\mathrm{C}_{\mathrm{T}}$ was used for the quantification for each sample. Data were normalized to Gapdh by the comparative $\mathrm{C}_{\mathrm{T}}\left(2^{-\Delta \Delta \mathrm{CT}}\right)$ method. See Supplementary Methods for details.

\section{CAMP induction assay}

Intact Htr4 (WT) and mutant Htr4 ${ }^{\text {delEs }}$ (delE5) cDNA coding sequences (CDSs) obtained from the DG of cKO and WT mice were cloned into a mammalian expression plasmid as described in Supplementary Methods. HEK293T cells were transfected with the delE5, WT, or EGFP plasmids. Forty-eight hrs after the transfection, cells were incubated in stimulation buffer consisting of DMEM + 0.5 mM IBMX (Sigma Aldrich, St. Louis, MO) for $30 \mathrm{~min}$. For cAMP induction, cells were further incubated in either stimulation buffer or $100 \mu \mathrm{M}$ Zacopride (Tocris Bioscience, Bio-Techne, Minneapolis, MN) in stimulation buffer for $45 \mathrm{~min}$. cAMP levels in the supernatants were measured by monoclonal anti-cAMP antibody-based direct cAMP ELISA kit according to the manufacturer's guidelines (NewEast Biosciences, King of Prussia, PA). Four biological replicates and two technical replicates were performed for each experimental group. The cAMP level of each biological replicate was normalized to its mean protein concentration measured using Qubit protein assay kit (Thermo Fisher Scientific, Waltham, MA). See Supplementary Methods for detailed description.

\section{Immunohistochemistry}

Immunohistochemistry and immunofluorescent staining were carried out on free-floating brain sections and imaged on either a Zeiss LSM700 confocal microscope or Zeiss Axioskop 2 microscope. Brightness was optimized using ImageJ software post-acquisition. For the quantification of neurogenesis, an experimenter blinded to genotype counted number of DCX-positive (DCX+) cells in the DG granule cell layer (GCL) in every sixth $40 \mu \mathrm{m}$ thick coronal section through the entire hippocampus of WT or cKO mice. Neurogenesis was calculated as the number of DCX + cells per area of GCL within a subdivision and values for each animal (cKO and WT) was normalized to the WT mean for each subdivision. For details on experimental procedures and antibodies used see Supplementary Methods.

\section{Fluorescent in-situ hybridization (FISH)}

The RNAscope Multiplex Fluorescent Reagent Kit V2 (Advanced Cell Dagnostics, Newark, CA) was used for Htr4 FISH. See Supplementary Methods for details.

\section{Translating ribosome affinity purification (TRAP)}

Affinity purification of EGFP-tagged polysomes and RNA extraction were performed as previously described [51] with minor modifications as detailed in Supplementary Methods. Biological replicates consisted of relevant brain tissue pooled from one male and one female mouse.

\section{RNA sequencing (RNA-seq)}

RNA was amplified using the Ovation RNA-Seq System V2 Kit (NuGEN, Redwood City, CA) and RNA-seq libraries were prepared using the TruSeq RNA Sample Preparation Kit v2 (Illumina, San Diego, CA) following manufacturer's protocols. Libraries were sequenced at The Rockefeller University Genomics Resource Center on the Illumina NextSeq 500 platform. RNA-seq reads were aligned to annotated exons using the mm10 mouse reference genome (UCSC) with STAR (2.4.2a) [91]. The quantification of aligned reads was done using HTSeq framework (0.6.0) [92]. Differential expression analysis was performed using DESeq2 [93]. Differentially expressed (DE) genes for each analysis were determined based on adjusted $p$ values (p-adj) and reported in the Results section or Figure Legends. See Supplementary Methods for further details.

\section{Electrophysiological recordings}

Mice of 8 weeks were used for slice electrophysiology. Slice preparation, data acquisition, and analysis were performed with experimenter blinded to mice genotype. See Supplementary Methods for detailed description.

\section{Statistics}

All statistical analysis was performed using GraphPad Prism 7 and 8, Microsoft Excel or R. Sample size was based on prior studies [5, 19]. Statistical parameters including the exact value of $n$, precision measures (mean $\pm \mathrm{SEM}$ ) and statistical 
significance are reported within the Results or the Figure Legends. Data were determined to be statistically significant when $p<0.05$ by two-way ANOVA (ordinary or repeated measures $[\mathrm{RM}]$ ) followed by post hoc Fisher's LSD test, oneway ANOVA followed by post hoc Fisher's LSD test, or twotailed unpaired $t$-test. All data met the assumptions of applied statistical tests. Statistical methods to analyze RNA-seq data are detailed in Supplementary Methods.

\section{Data availability}

RNA-seq data sets are available from the NCBI Gene Expression Omnibus series accession number GSE157607.

Acknowledgements This work was funded by NIH/NINDS grants R01NS091722 (EFS) and R21NS105047 (EFS), NIH/NIDA P30 Center DA035756 (NH, EFS), The Fisher Center for Alzheimer's Research Foundation (PG) and The Leon Black Family Foundation (PG). $\mathrm{NH}$ is also an investigator of the Howard Hughes Medical Institute (HHMI). We thank The Rockefeller University Genomics Resource Center, Transgenic Services Laboratory and Comparative Bioscience Center as well as the HHMI Janelia Research Campus Gene Targeting and Transgenics support team. We also thank Erika Andrade and Awni Mousa for assistance with bioinformatics analyses and Jodi Gresack for assistance and discussions regarding the behavioral studies. We thank Winrich Freiwald for guidance and David Rockefeller Graduate Program for its support.

Author contributions RK, NH, and EFS designed the study. RK, BWF, MNR, and EBH performed all experiments unless noted otherwise. LM conducted electrophysiology experiments. RK, LM, JLW-S, PG, NH, and EFS analyzed data. RK, LM, JLW-S, and EFS wrote the manuscript.

\section{Compliance with ethical standards}

Conflict of interest The authors declare that they have no conflict of interest.

Publisher's note Springer Nature remains neutral with regard to jurisdictional claims in published maps and institutional affiliations.

Open Access This article is licensed under a Creative Commons Attribution 4.0 International License, which permits use, sharing, adaptation, distribution and reproduction in any medium or format, as long as you give appropriate credit to the original author(s) and the source, provide a link to the Creative Commons license, and indicate if changes were made. The images or other third party material in this article are included in the article's Creative Commons license, unless indicated otherwise in a credit line to the material. If material is not included in the article's Creative Commons license and your intended use is not permitted by statutory regulation or exceeds the permitted use, you will need to obtain permission directly from the copyright holder. To view a copy of this license, visit http://creativecommons. org/licenses/by/4.0/.

\section{References}

1. Price JL, Drevets WC. Neural circuits underlying the pathophysiology of mood disorders. Trends Cogn Sci. 2012;16:61-71.
2. Ressler KJ, Mayberg HS. Targeting abnormal neural circuits in mood and anxiety disorders: from the laboratory to the clinic. Nat Neurosci. 2007;10:1116-24.

3. Krishnan V, Nestler EJ. The molecular neurobiology of depression. Nature. 2008;455:894-902.

4. Ferguson JM. SSRI antidepressant medications: adverse effects and tolerability. Prim Care Companion J Clin Psychiatry. 2001;3:22-7.

5. Schmidt EF, Warner-Schmidt JL, Otopalik BG, Pickett SB, Greengard P, Heintz N. Identification of the cortical neurons that mediate antidepressant responses. Cell. 2012;149:1152-63.

6. Warner-Schmidt JL, Schmidt EF, Marshall JJ, Rubin AJ, ArangoLievano M, Kaplitt MG, et al. Cholinergic interneurons in the nucleus accumbens regulate depression-like behavior. Proc Natl Acad Sci USA. 2012;109:11360-5.

7. Bagot RC, Cates HM, Purushothaman I, Lorsch ZS, Walker DM, Wang J, et al. Circuit-wide transcriptional profiling reveals brain region-specific gene networks regulating depression susceptibility. Neuron. 2016;90:969-83.

8. Bagot RC, Cates HM, Purushothaman I, Vialou V, Heller EA, Yieh L, et al. Ketamine and imipramine reverse transcriptional signatures of susceptibility and induce resilience-specific gene expression profiles. Biol Psychiatry. 2017;81:285-95.

9. Hannon J, Hoyer D. Molecular biology of 5-HT receptors. Behav Brain Res. 2008;195:198-213.

10. Bockaert J, Claeysen S, Compan V, Dumuis A. 5-HT(4) receptors: history, molecular pharmacology and brain functions. Neuropharmacology. 2008;55:922-31.

11. Andrade R. Electrophysiological properties of gas-coupled 5-HT receptors (5-HT4, 5-HT6, 5-HT7). In: Roth BL (ed). The serotonin receptors: from molecular pharmacology to human therapeutics. Totowa, NJ: Humana Press; 2006, pp. 481-94.

12. Marner L, Gillings N, Madsen K, Erritzoe D, Baare WF, Svarer C, et al. Brain imaging of serotonin 4 receptors in humans with [11C] SB207145-PET. Neuroimage. 2010;50:855-61.

13. Rosel P, Arranz B, Urretavizcaya M, Oros M, San L, Navarro MA. Altered 5-HT2A and 5-HT4 postsynaptic receptors and their intracellular signalling systems IP3 and cAMP in brains from depressed violent suicide victims. Neuropsychobiology. 2004;49:189-95.

14. Ohtsuki T, Ishiguro H, Detera-Wadleigh SD, Toyota T, Shimizu $\mathrm{H}$, Yamada $\mathrm{K}$, et al. Association between serotonin 4 receptor gene polymorphisms and bipolar disorder in Japanese case-control samples and the NIMH Genetics Initiative Bipolar Pedigrees. Mol psychiatry. 2002;7:954-61.

15. Faye C, Hen R, Guiard BP, Denny CA, Gardier AM, MendezDavid I, et al. Rapid anxiolytic effects of RS67333, a serotonin type 4 receptor agonist, and diazepam, a benzodiazepine, are mediated by projections from the prefrontal cortex to the dorsal raphe nucleus. Biol Psychiatry. 2020;87:514-25.

16. Lucas G, Rymar VV, Du J, Mnie-Filali O, Bisgaard C, Manta S, et al. Serotonin(4) (5-HT(4)) receptor agonists are putative antidepressants with a rapid onset of action. Neuron. 2007;55:712-25.

17. Mendez-David I, David DJ, Darcet F, Wu MV, Kerdine-Romer S, Gardier AM, et al. Rapid anxiolytic effects of a 5-HT(4) receptor agonist are mediated by a neurogenesis-independent mechanism. Neuropsychopharmacology. 2014;39:1366-78.

18. Pascual-Brazo J, Castro E, Diaz A, Valdizan EM, Pilar-Cuellar F, Vidal R, et al. Modulation of neuroplasticity pathways and antidepressant-like behavioural responses following the shortterm (3 and 7 days) administration of the 5-HT(4) receptor agonist RS67333. Int J Neuropsychopharmacol. 2012;15:631-43.

19. Warner-Schmidt JL, Flajolet M, Maller A, Chen EY, Qi H, Svenningsson $\mathrm{P}$, et al. Role of p11 in cellular and behavioral 
effects of 5-HT4 receptor stimulation. J Neurosci. 2009;29:1937-46.

20. Lucas G, Du J, Romeas T, Mnie-Filali O, Haddjeri N, Pineyro G, et al. Selective serotonin reuptake inhibitors potentiate the rapid antidepressant-like effects of serotonin 4 receptor agonists in the rat. PLoS One. 2010;5:e9253.

21. Compan V, Zhou M, Grailhe R, Gazzara RA, Martin R, Gingrich $\mathrm{J}$, et al. Attenuated response to stress and novelty and hypersensitivity to seizures in 5-HT4 receptor knock-out mice. J Neurosci. 2004;24:412-9.

22. Eisch AJ, Petrik D. Depression and hippocampal neurogenesis: a road to remission? Science. 2012;338:72-5.

23. Bonaventure $\mathrm{P}$, Hall $\mathrm{H}$, Gommeren $\mathrm{W}$, Cras $\mathrm{P}$, Langlois X, Jurzak $\mathrm{M}$, et al. Mapping of serotonin 5-HT(4) receptor mRNA and ligand binding sites in the post-mortem human brain. Synapse. 2000;36:35-46.

24. Hegde SS, Eglen RM. Peripheral 5-HT4 receptors. Faseb J. 1996;10:1398-407.

25. Kaumann AJ, Levy FO. 5-hydroxytryptamine receptors in the human cardiovascular system. Pharm Ther. 2006;111:674-706.

26. Tonini M, Pace F. Drugs acting on serotonin receptors for the treatment of functional GI disorders. Dig Dis. 2006;24:59-69.

27. Anacker C, Hen R. Adult hippocampal neurogenesis and cognitive flexibility - linking memory and mood. Nat Rev Neurosci. 2017; 18:335-46.

28. Hultman R, Ulrich K, Sachs BD, Blount C, Carlson DE, Ndubuizu N, et al. Brain-wide electrical spatiotemporal dynamics encode depression vulnerability. Cell. 2018;173:166-80.e114.

29. Tanaka KF, Samuels BA, Hen R. Serotonin receptor expression along the dorsal-ventral axis of mouse hippocampus. Philos Trans R Soc Lond B Biol Sci. 2012;367:2395-401.

30. Gong S, Doughty M, Harbaugh CR, Cummins A, Hatten ME, Heintz N, et al. Targeting Cre recombinase to specific neuron populations with bacterial artificial chromosome constructs. J Neurosci. 2007;27:9817-23.

31. Zhou P, Zhang Y, Ma Q, Gu F, Day DS, He A, et al. Interrogating translational efficiency and lineage-specific transcriptomes using ribosome affinity purification. Proc Natl Acad Sci USA. 2013;110:15395-15400.

32. Imoto Y, Kira T, Sukeno M, Nishitani N, Nagayasu K, Nakagawa $\mathrm{T}$, et al. Role of the 5-HT4 receptor in chronic fluoxetine treatment-induced neurogenic activity and granule cell dematuration in the dentate gyrus. Mol Brain. 2015;8:29.

33. Warner-Schmidt J. Treating the brain deep down: Short-circuiting depression. Nat Med. 2013;19:680-1.

34. Hascoët M, Bourin $M$. The forced swimming test in mice: a suitable model to study antidepressants. In: Gould TD (ed). Mood and anxiety related phenotypes in mice. Totowa, NJ; Humana Press: 2009. pp. 85-118.

35. O'Leary OF, Cryan JF. The tail-suspension test: a model for characterizing antidepressant activity in mice. In: Mood and anxiety related phenotypes in mice: Characterization using behavioral tests. Totowa, NJ: Humana Press; 2009. pp. 119-37.

36. Hascoët $M$, Bourin $M$. The forced swimming test in mice: a suitable model to study antidepressants. Humana Press; 2009. pp. 85-118.

37. David DJ, Samuels BA, Rainer Q, Wang JW, Marsteller D, Mendez I, et al. Neurogenesis-dependent and -independent effects of fluoxetine in an animal model of anxiety/depression. Neuron. 2009;62:479-93.

38. Griebel G, Simiand J, Serradeil-Le Gal C, Wagnon J, Pascal M, Scatton B, et al. Anxiolytic- and antidepressant-like effects of the non-peptide vasopressin V1b receptor antagonist, SSR149415, suggest an innovative approach for the treatment of stress-related disorders. Proc Natl Acad Sci USA. 2002;99:6370-5.
39. Strekalova T, Spanagel R, Bartsch D, Henn FA, Gass P. Stressinduced anhedonia in mice is associated with deficits in forced swimming and exploration. Neuropsychopharmacology. 2004;29:2007-17.

40. Kheirbek MA, Drew LJ, Burghardt NS, Costantini DO, Tannenholz L, Ahmari SE, et al. Differential control of learning and anxiety along the dorsoventral axis of the dentate gyrus. Neuron. 2013;77:955-68.

41. Gould TD, Dao DT, Kovacsics CE. The open field test. In: Gould TD (ed). Mood and anxiety related phenotypes in mice: characterization using behavioral tests. Totowa, NJ: Humana Press; 2009. pp. 1-20.

42. Samuels BA, Hen R. Novelty-suppressed feeding in the mouse. In: Gould TD (ed). Mood and anxiety related phenotypes in mice: characterization using behavioral tests. Volume II. Totowa, NJ: Humana Press; 2011. pp. 107-21.

43. Walf AA, Frye CA. The use of the elevated plus maze as an assay of anxiety-related behavior in rodents. Nat Protoc. 2007;2:322-8.

44. Gould TD, Dao DT, Kovacsics CE. The open field test. Humana Press; 2009. pp. 1-20.

45. Bailey KR, Crawley JN. Anxiety-related behaviors in mice. In: Methods of behavioral analysis in neuroscience. 2nd ed. Boca Raton, FL, US: CRC Press/Routledge/Taylor \& Francis Group; 2009. pp. 77-101.

46. Kaviani H, Gray JA, Checkley SA, Raven PW, Wilson GD, Kumari V. Affective modulation of the startle response in depression: influence of the severity of depression, anhedonia, and anxiety. J Affect Disord. 2004;83:21-31.

47. Miller MW, Gronfier C. Diurnal variation of the startle reflex in relation to HPA-axis activity in humans. Psychophysiology. 2006;43:297-301.

48. Allen NB, Trinder J, Brennan C. Affective startle modulation in clinical depression: preliminary findings. Biol Psychiatry. 1999;46:542-50.

49. Giakoumaki SG, Bitsios P, Frangou S, Roussos P, Aasen I, Galea A, et al. Low baseline startle and deficient affective startle modulation in remitted bipolar disorder patients and their unaffected siblings. Psychophysiology. 2010;47:659-68.

50. O'Brien-Simpson L, Di Parsia P, Simmons JG, Allen NB. Recurrence of major depressive disorder is predicted by inhibited startle magnitude while recovered. J Affect Disord. 2009;112:243-9.

51. Heiman M, Kulicke R, Fenster RJ, Greengard P, Heintz N. Cell type-specific mRNA purification by translating ribosome affinity purification (TRAP). Nat Protoc. 2014;9:1282-91.

52. Heiman M, Schaefer A, Gong S, Peterson JD, Day M, Ramsey $\mathrm{KE}$, et al. A translational profiling approach for the molecular characterization of CNS cell types. Cell. 2008;135:738-48.

53. Vidal R, Valdizan EM, Mostany R, Pazos A, Castro E. Long-term treatment with fluoxetine induces desensitization of 5-HT4 receptor-dependent signalling and functionality in rat brain. $\mathrm{J}$ Neurochem. 2009;110:1120-7.

54. Lucas G, Compan V, Charnay Y, Neve RL, Nestler EJ, Bockaert $\mathrm{J}$, et al. Frontocortical 5-HT4 receptors exert positive feedback on serotonergic activity: viral transfections, subacute and chronic treatments with 5-HT4 agonists. Biol Psychiatry. 2005;57:918-25.

55. Castello J, Lefrancois B, Flajolet M, Greengard P, Friedman E, Rebholz H. CK2 regulates 5-HT4 receptor signaling and modulates depressive-like behavior. Mol Psychiatry. 2018;23:872-82.

56. Sargin D, Chottekalapanda RU, Perit KE, Yao V, Chu D, Sparks DW, et al. Mapping the physiological and molecular markers of stress and SSRI antidepressant treatment in S100a10 corticostriatal neurons. Mol Psychiatry. 2019;25:1112-29.

57. Jean A, Conductier G, Manrique C, Bouras C, Berta P, Hen R, et al. Anorexia induced by activation of serotonin 5-HT4 receptors 
is mediated by increases in CART in the nucleus accumbens. Proc Natl Acad Sci USA. 2007;104:16335-40.

58. Jean A, Laurent L, Bockaert J, Charnay Y, Dusticier N, Nieoullon A, et al. The nucleus accumbens 5-HTR(4)-CART pathway ties anorexia to hyperactivity. Transl Psychiatry. 2012;2:e203.

59. Andrade R, Chaput Y. 5-Hydroxytryptamine4-like receptors mediate the slow excitatory response to serotonin in the rat hippocampus. J Pharm Exp Ther. 1991;257:930-7.

60. Torres GE, Arfken CL, Andrade R. 5-Hydroxytryptamine4 receptors reduce afterhyperpolarization in hippocampus by inhibiting calcium-induced calcium release. Mol Pharm. 1996;50:1316-22.

61. Torres GE, Chaput Y, Andrade R. Cyclic AMP and protein kinase A mediate 5-hydroxytryptamine type 4 receptor regulation of calcium-activated potassium current in adult hippocampal neurons. Mol Pharm. 1995;47:191-7.

62. Hoyer D, Hannon JP, Martin GR. Molecular, pharmacological and functional diversity of 5-HT receptors. Pharm Biochem Behav. 2002;71:533-54.

63. Barthet G, Framery B, Gaven F, Pellissier L, Reiter E, Claeysen S, et al. 5-hydroxytryptamine 4 receptor activation of the extracellular signal-regulated kinase pathway depends on Src activation but not on $\mathrm{G}$ protein or beta-arrestin signaling. Mol Biol Cell. 2007;18:1979-91.

64. Simms BA, Zamponi GW. Neuronal voltage-gated calcium channels: structure, function, and dysfunction. Neuron. 2014;82:24-45.

65. Thomas GM, Huganir RL. MAPK cascade signalling and synaptic plasticity. Nat Rev Neurosci. 2004;5:173-83.

66. Medrihan L, Sagi Y, Inde Z, Krupa O, Daniels C, Peyrache A, et al. Initiation of behavioral response to antidepressants by cholecystokinin neurons of the dentate gyrus. Neuron. 2017;95:564-76 e564.

67. Anacker C, Luna VM, Stevens GS, Millette A, Shores R, Jimenez JC, et al. Hippocampal neurogenesis confers stress resilience by inhibiting the ventral dentate gyrus. Nature. 2018;559:98-102.

68. Samuels BA, Anacker C, Hu A, Levinstein MR, Pickenhagen A, Tsetsenis T, et al. 5-HT1A receptors on mature dentate gyrus granule cells are critical for the antidepressant response. Nat Neurosci. 2015;18:1606-16.

69. Wang X, Zhang D, Lu XY. Dentate gyrus-CA3 glutamate release/ NMDA transmission mediates behavioral despair and antidepressant-like responses to leptin. Mol psychiatry. 2015;20:509-19.

70. Kobayashi K, Ikeda Y, Haneda E, Suzuki H. Chronic fluoxetine bidirectionally modulates potentiating effects of serotonin on the hippocampal mossy fiber synaptic transmission. J Neurosci. 2008;28:6272-80.

71. Costall B, Naylor RJ. The influence of 5-HT2 and 5-HT4 receptor antagonists to modify drug induced disinhibitory effects in the mouse light/dark test. Br J Pharm. 1997;122:1105-18.

72. Jimenez JC, Su K, Goldberg AR, Luna VM, Biane JS, Ordek G, et al. Anxiety cells in a hippocampal-hypothalamic circuit. Neuron. 2018;97:670-83 e676.

73. Parfitt GM, Nguyen R, Bang JY, Aqrabawi AJ, Tran MM, Seo $\mathrm{DK}$, et al. Bidirectional control of anxiety-related behaviors in mice: role of inputs arising from the ventral hippocampus to the lateral septum and medial prefrontal cortex. Neuropsychopharmacology. 2017;42:1715-28.

74. Duric V, Duman RS. Depression and treatment response: dynamic interplay of signaling pathways and altered neural processes. Cell Mol Life Sci. 2013;70:39-53.

75. Floriou-Servou A, von Ziegler L, Stalder L, Sturman O, Privitera M, Rassi A, et al. Distinct proteomic, transcriptomic, and epigenetic stress responses in dorsal and ventral hippocampus. Biol Psychiatry. 2018;84:531-41.

76. Gray JD, Rubin TG, Kogan JF, Marrocco J, Weidmann J, Lindkvist $\mathrm{S}$, et al. Translational profiling of stress-induced neuroplasticity in the CA3 pyramidal neurons of BDNF Val66Met mice. Mol Psychiatry. 2016;23:904-13.

77. Pohodich AE, Yalamanchili H, Raman AT, Wan YW, Gundry M, Hao $\mathrm{S}$, et al. Forniceal deep brain stimulation induces gene expression and splicing changes that promote neurogenesis and plasticity. eLife. 2018;7:e34031. https://doi.org/10.7554/eLife. 34031

78. Duman RS, Aghajanian GK. Synaptic dysfunction in depression: potential therapeutic targets. Science. 2012;338:68-72.

79. McEwen BS, Nasca C, Gray JD. Stress effects on neuronal structure: hippocampus, amygdala, and prefrontal cortex. Neuropsychopharmacology. 2016;41:3-23.

80. Santarelli L, Saxe M, Gross C, Surget A, Battaglia F, Dulawa S, et al. Requirement of hippocampal neurogenesis for the behavioral effects of antidepressants. Science. 2003;301:805-9.

81. Sahay A, Scobie KN, Hill AS, O'Carroll CM, Kheirbek MA, Burghardt NS, et al. Increasing adult hippocampal neurogenesis is sufficient to improve pattern separation. Nature. 2011;472:466-70

82. Strange BA, Witter MP, Lein ES, Moser EI. Functional organization of the hippocampal longitudinal axis. Nat Rev Neurosci. 2014;15:655-69.

83. Boldrini M, Underwood MD, Hen R, Rosoklija GB, Dwork AJ, John Mann J, et al. Antidepressants increase neural progenitor cells in the human hippocampus. Neuropsychopharmacology. 2009;34:2376-89.

84. Zhou QG, Lee D, Ro EJ, Suh H. Regional-specific effect of fluoxetine on rapidly dividing progenitors along the dorsoventral axis of the hippocampus. Sci Rep. 2016;6:35572.

85. Wu MV, Hen R. Functional dissociation of adult-born neurons along the dorsoventral axis of the dentate gyrus. Hippocampus. 2014;24:751-61.

86. Zheng J, Jiang YY, Xu LC, Ma LY, Liu FY, Cui S, et al. Adult hippocampal neurogenesis along the dorsoventral axis contributes differentially to environmental enrichment combined with voluntary exercise in alleviating chronic inflammatory pain in mice. $\mathbf{J}$ Neurosci. 2017;37:4145-57.

87. Ansorge MS, Morelli E, Gingrich JA. Inhibition of serotonin but not norepinephrine transport during development produces delayed, persistent perturbations of emotional behaviors in mice. $\mathrm{J}$ Neurosci. 2008;28:199-207.

88. Baek IS, Park JY, Han PL. Chronic antidepressant treatment in normal mice induces anxiety and impairs stress-coping ability. Exp Neurobiol. 2015;24:156-68.

89. Birkett MA, Shinday NM, Kessler EJ, Meyer JS, Ritchie S, Rowlett JK. Acute anxiogenic-like effects of selective serotonin reuptake inhibitors are attenuated by the benzodiazepine diazepam in BALB/c mice. Pharm Biochem Behav. 2011;98:544-51.

90. Kobayashi K, Ikeda Y, Suzuki H. Behavioral destabilization induced by the selective serotonin reuptake inhibitor fluoxetine. Mol Brain. 2011;4:12.

91. Dobin A, Davis CA, Schlesinger F, Drenkow J, Zaleski C, Jha S, et al. STAR: ultrafast universal RNA-seq aligner. Bioinformatics. 2013;29:15-21.

92. Anders S, Pyl PT, Huber W. HTSeq-a Python framework to work with high-throughput sequencing data. Bioinformatics. 2015;31:166-9.

93. Love MI, Huber W, Anders S. Moderated estimation of fold change and dispersion for RNA-seq data with DESeq2. Genome Biol. 2014;15:550. 